\title{
Resiliencia educativa de estudiantes ante los riesgos sociales generados por la barras juveniles de fútbol en Honduras
}

\section{Educational resilience from students due to the social risks generated by young soccer fans in Honduras}

\author{
PhD. Zoila Suyapa Padilla \\ Directora Instituto de Investigación y Evaluación Educativa y Sociales \\ Universidad Pedagógica Nacional Francisco Morazán
}

\begin{abstract}
Resumen
En las sociedades afectadas por la violencia, los niños, niñas, adolescentes y los jóvenes presentan necesidades y vulnerabilidades específicas, como lo demuestran los altos índices de problemas sociales en este nivel de la población: bajo rendimiento escolar, involucración en pandillas, y carencias afectivas y materiales. A la vez que son afectados, los adolescentes también se convierten en protagonistas al no existir un mecanismo social capaz de intervenir a tiempo en el ciclo reproductivo de la violencia, prestándoles la ayuda eficaz y también las oportunidades de un desarrollo social sano.
\end{abstract}

En Honduras, el contexto de violencia ha ido en aumento y ha evolucionado en su afectación a la niñez y la juventud, incluyendo aquellos que ya se encuentran dentro del sistema educativo. Las comunidades educativas constituyen una de las principales fuentes de protección al alcance de los adolescentes y su familia por ser el 
hábitat principal en que conviven los estudiantes en esta edad. Sin embargo, la mayoría de las veces la escuela no está lista para entender la complej idad del fenómeno de la violencia, su naturaleza y evolución. En consecuencia, las instituciones educativas se vuelven focos generadores de la violencia en vez de espacios de protección. Cuando las medidas que se toman frente a los riesgos que afrontan los estudiantes no logran los impactos esperados, los ciclos de violencia tienden a repetirse con las generaciones siguientes y a evolucionar de manera negativa.

Desde esta perspectiva, el Instituto de Investigación Educativas y Sociales de la Universidad Pedagógica Nacional (UPNFM) en Honduras con el patrocinio y asistencia técnica del Banco Mundial, ha desarrollado el presente estudio sobre la evolución de la violencia generada por barras juveniles de fútbol en los centros educativos, al igual que la contribución que brinda el entender los mecanismos de Resiliencia que desarrollan los estudiantes de secundaria frente a este fenómeno. Los hallazgos derivados de este estudio tienen como fin contribuir a desarrollar políticas educativas pertinentes para incidir en estrategias que permitan prevenir, atender y mitigar los efectos de este tipo de violencia al interior de los centros educativos y apoyar a los estudiantes y sus familias en el desarrollo de conductas psico-afectivas que les permitan desenvolverse en situaciones de alta vulnerabilidad social. Esta tarea educativa, resulta tan ineludible para el sector educativo como lo es la de promover los aprendizaj es académicos.

El estudio está basado en técnicas cualitativas y cuantitativas, tomando una muestra de 612 estudiantes de noveno grado, con entrevistas a padres de familia, docentes y directivos de dos centros educativos, uno en la ciudad de Tegucigalpa y el otro en la ciudad de Choluteca.

En ambos centros educativos, los factores protectores percibidos por los estudiantes ante la exposición a la violencia, figuran los de contar con vínculos de familiares, amigos y maestros, unido a un fuerte sentimiento de pertenencia tanto a su familia, como a su institución educativa y al país. Todos estos factores contribuyen a una auto-percepción positiva sobre sus habilidades y conocimientos, 
Resiliencia educativa de estudiantes ante los riesgos sociales generados por la barras juveniles de fútbol en Honduras

que los lleva a manifestar metas muy altas para su futuro, en las que destaca, en primer lugar, completar su proyecto educativo.

Palabras Clave: Resiliencia Educativa, Barras J uveniles de Futbol. Tercer Ciclo de Educación Básica.

Abstract: In societies affected by violence, children, adolescents and young people have specific needs and vulnerabilities, as evidenced by high rates of social problems in this population: poor school performance, involvement in gangs, and emotional deprivation and materials. While affected, teens also become protagonist in the absence of a social mechanism to intervene early in the reproductive cycle of violence by providing them with effective support and opportunities for healthy social development.

In Honduras, the context of violence has increased and evolved in the implication it has on children and youth, including those who are already within the educational system. Educational communities are one of the main sources of protection available to adolescents and their families, as the environment where students coexist at this age. However, most of the time the school is not ready to understand the complexity of the phenomenon of violence, its nature, and evolution

Consequently, educational institutionsbecome generators of violence instead of protective spaces. When the measures taken against the risks faced by students fail the expected impacts, cycles of violence tend to recur with the next generations and evolving negatively. From this perspective, the Institute for Educational and Social Research of the National Pedagogical University (UPNFM) in Honduras with the sponsorship and support of the World Bank, has developed the present study on the evolution of the violence cause by youth soccer fans in schools, as well as the contribution provided by the understanding of the mechanisms of resilience that high school students develop due to this phenomenon. The findings from this study are intended to help develop relevant policies to influence educational strategies to prevent, respond to, and mitigate the effects of such violence within schools, and support students and their families in developing psycho-emotional behaviors that 
allow them to deal with situations of high social vulnerability. This educational task is ineludible for the educational system, as it is promoting academic learning.

The study is based on qualitative and quantitative techniques, taking a sample of 612 ninth graders, interviews with parents, teachers, and principals of two schools, one in the city of Tegucigalpa and one in the city of Choluteca. In both schools, the protective factors perceived by students from exposure to violence, include links to have family, friends, and teachers, coupled with a strong sense of belonging to your family, your school and the country. All these factors contribute to a positive self-perception of their skills and knowledge, which leads them to express very high goals for their future, most notably, complete their educational project.

Key words: Educational Resilience, Youth Soccer fans, Third Cycle of Basic Education

\section{Antecedentes}

En los inicios del Siglo XXI, Honduras enfrenta muchos desafíos que la posicionan como uno de los países que difícilmente alcanzará las Metas del Milenio planteadas por las Naciones Unidas para el año 2015. Sin embargo, además de los desafíos de lograr Educación para Todos, Honduras confronta igualmente una ola de violencia sin precedencia, particularmente para su población más joven que constituye el grupo etario mayor, y que ha logrado impactar los centros educativos desde su interior. Por lo tanto, el país tiene un reto doble: continuar los esfuerzos para aumentar sus metas educativas y frenar la ola de violencia que no sólo afecta las calles sino de forma significativa los centros de estudio.

Esta sección hace un resumen de las prioridades en materia educativa de Honduras, los nuevos retos presentados por la violencia, y una forma muy particular de cómo la violencia se concretiza al interior de las instituciones educativas: las barras de fútbol. 
Resiliencia educativa de estudiantes ante los riesgos sociales generados por la barras juveniles de fútbol en Honduras

\section{Prioridades en materia educativa de Honduras}

Según la Encuesta Permanente de Hogares de Propósitos Múltiples del año 2008 (INE) en Honduras, hay 2,976,918 jóvenes entre 12 y 30 años, lo que representa el $38.7 \%$ del total de la población. Honduras invierte el $7.2 \%$ del PIB en educación. Sin embargo, un poco más del $80 \%$ del presupuesto asignado a la Secretaria de Educación y a la Universidad Nacional Autónoma de Honduras (UNAH), se invierte en sueldos y salarios. Según datos de 2008, el $94.2 \%$ de los/ las jóvenes han cursado la educación primaria, $45.7 \%$ educación secundaria y el $6.7 \%$ educación superior. Las mujeres jóvenes superan a los hombres jóvenes en educación primaria, media y superior.

El aumento del acceso a la educación y la tecnología es profundamente desigual. Los jóvenes de zonas pobres y rurales cuentan con menores posibilidades de acceder a una educación digna respecto a los jóvenes de zonas urbanas y capas medias, medias altas. En Honduras la educación secundaria no ha sido obligatoria hasta el año 2012 en el que la Ley Fundamental de Educación extiende la obligatoriedad hasta el noveno grado. Para 2010, la cobertura del tercer ciclo fue de $39.534 \%$ y la del ciclo diversificado, de $27.6 \%$ La baja cobertura de la educación secundaria es especialmente grave en el área rural. La cobertura del ciclo diversificado en el área rural es de $15 \%$

Otro elemento importante, aún en los datos oficiales, es qué la mitad de los egresados de educación primaria (hasta sexto grado) no entran a la educación secundaria, y un porcentaje mucho menor llega a cursar la universidad. Es decir, la inmensa mayoría de la población hondureña no llega a cursar estudios universitarios (94.3\%).

\section{Contexto de violencia social}

Unido a la problemática educativa particular, en los últimos cuatro años en el país se agudiza el fenómeno de la violencia de tal forma que, actual mente Honduras es catalogado como el país con los índices más altos de violencia a nivel mundial, de acuerdo al Observatorio de la Violencia (2011) de la UNAH (85.5 pccmh en 2012). Aunque el fenómeno de la violencia muestra muchas dimensiones, su impacto 
en los jóvenes que asisten a centros de secundaria podría tener serias repercusiones sociales, facilitadas por la vulnerabilidad de esta población, como se ha descrito anteriormente.

En Honduras se da una proporción de delincuencia juvenil en alarmante aumento. Esta violencia juvenil se ha manifestado en formas de maras, drogas, violencia callejera y robo. En la década del 80 los casos atendidos en el Proyecto Victoria (un proyecto de reinserción social para jóvenes) por drogas ilegales, catalogadas blandas como la marihuana, floricunda-planta alucinógena y pastillas fue de un $50 \%$ y por alcohol un $30 \%$ Con antecedentes de robo y asalto se presentaba un $20 \%$ y por crímenes un $1 \%$ Actualmente, por consumo de drogas ilegal es como la cocaína y crack (narcóticos) ingresan un $90 \%$ por alcohol $10 \%$, han cometido robo y asalto un $75 \%$ y por crímenes o asesinatos un 40\% (Fumero 2011).

Sin embargo, existe una forma adicional de violencia que se ha generado desde lo que podría ser considerado un contexto no tradicional: las barras juveniles de fútbol. La problemática de las barras j uveniles de fútbol en Honduras aparece inserta en el contexto de evolución de la violencia social en el país, afectando los centros educativos desde su interior. Para poder responder pertinentemente a esta mutación de la violencia (de lo tradicionalmente ilícito a maneras que inicialmente parecen inofensivas, como las barras de futbol) es importante entender tanto los riesgos que afectan a los estudiantes, como sus mecanismos de resiliencia o de afrontamiento hacia la violencia.

El incremento de la violencia, las barras de futbol y la necesidad de respuesta del sector educativo

En la actualidad, el fútbol latinoamericano está viviendo una ola de violencia en los escenarios deportivos realizados por "Barras Bravas" que en el pasado eran un grupo de personas que se unían con el fin de alentar a los equipos. El amor apasionado por el equipo de fútbol hace que exista la rivalidad, y esta conlleva a actos de violencia que se han trasladado a espacios públicos (calles, barrios, centros educativos, parques, conciertos, etc.).

En Honduras existen diferentes grupos de las Ilamadas Barras Bravas. 
Formadas sobre todo, por jóvenes. Las más famosas son la "Ultrafiel" del Club Olimpia, la "REVO" y la "Macroazzurra" del Motagua, los "Megalocos" del Real España y la "Furia Verde" del Marathón. Las dos primeras son las dos Barras más representativas de la ciudad de Tegucigalpa y entre ellas existe una rivalidad que viene de muchos años atrás; las dos últimas son de San Pedro Sula, aunque igual existe una rivalidad fuerte entre la "Ultrafiel" y los "Megalocos". Estas barras se nutren de jóvenes de variada procedencia social, sin embrago, un espacio de reclutamiento preferencial parece ser el de los centros educativos. A finales del año 2012, los incidentes violentos protagonizados por las barras juveniles de fútbol acapararon las primeras planas de los medios informativos. En los primeros meses del 2013 este protagonismo se ha reflejado en noticias referidas, ya no solamente a violencia externa a los centros educativos, sino actos violentos al interior de los mismos.

Este contexto de violencia juvenil no se desarrolla en un vacío social; y esto significa que su crecimiento o mitigación es afectado por un entorno institucional, el cual tiene que ver con decisiones políticas, con un marco jurídico establecido y con el comportamiento de las instituciones que deben lidiar con la problemática. Sin embargo, las políticas y estrategias de respuesta a la violencia juvenil requieren conocer dos aspectos importantes: los riesgos mismos que enfrentan la juventud, pero también sus mecanismos de afrontamiento y de búsqueda de bienestar. Esta última perspectiva es la que brinda el lente de la resiliencia.

\section{Objetivos del Estudio}

Con el fin de posibilitar una atención estratégica positiva ante los riesgos de la violencia en el sector educativo, con asistencia técnica del Banco Mundial la Universidad Pedagógica Nacional Francisco Morazán desarrolló en el año 2012 dos estudios de casos en centros educativos ubicados en escenarios de riesgo de violencia generada por barras juveniles de fútbol.

Específicamente, el estudio se orienta a conocer la perspectiva de los actores (estudiantes, personal de los centros educativos y pa- 
Zoila Suyapa Padilla

dres de familia) sobre los siguientes elementos:

1. ¿Qué tipo de riesgos (adversidad externa) enfrentan los estudiantes de ambos centros educativos?

2. ¿Cuáles son los mecanismos de resiliencia que desarrollan los estudiantes de ambos centros para permanecer en su proyecto educativo en un contexto de riesgo?

3. ¿Cuáles son las oportunidades percibidas tanto dentro como fuera del centro, que funcionan como factores de protección frente al riesgo representado por la exposición a barras juveniles?

\section{Ruta del Estudio}

El estudio desarrolló dos estudios de caso en centros educativos: el Instituto Central Vicente Cáceres de Tegucigalpa y el Centro Básico Ricardo Soriano de la ciudad de Choluteca. En ambos centros se trabajó con la población total del noveno grado (565 estudiantes) a los que se les aplicó un Cuestionario previamente validado, para posteriormente desarrollar entrevistas a profundidad con casos seleccionados.

Los directores de los dos centros fueron entrevistados así como los orientadores, consejeros, docentes, guardias y personal de cafeterías. Con los padres y madres de familia se realizaron grupos focales, tanto en el Instituto Central como en el Centro Básico Ricardo Soriano. Para realizar el proceso de investigación, se siguieron las normas éticas recomendadas lo que incluye la firma del consentimiento informado por cada uno de los actores participantes.

El abordaje participativo incluyó no sólo los actores sino también, la interacción entre un equipo de investigadores de la Universidad Pedagógica Nacional Francisco Morazán (UPNFM), apoyados por estudiantes de la misma institución como asistentes de investigación. El equipo técnico del programa de Resiliencia del Banco Mundial ${ }^{1}$ brindó apoyo a los investigadores de la UPN durante la Fase Preparatoria para el desarrollo de los marcos conceptuales del estudio y del cuestionario aplicado. En esta Fase se adaptó y validó el

\footnotetext{
${ }^{1}$ Education Resilience Approaches (ERA), bajo su nombre en inglés.
} 
Cuestionario CYRM-282, y se diseñaron y validaron los guiones para entrevistas y grupos focales (ver anexos 1-4). Además, en esta Fase se capacitó al equipo de siete estudiantes de la UPN que actuaron como investigadores noveles asociados a todo el proyecto, representando una ganancia significativa en el fortalecimiento de capacidades de futuros profesionales.

\section{Referente conceptual del estudio}

\subsection{Marco de referencia}

Frente al reto generado por el contexto de violencia social y su impacto en el sector educativo, se plantea la necesidad de consolidar una base conceptual que permita vislumbrar espacios para la intervención a partir de entender mejor los riesgos que enfrentan los jóvenes y sus mecanismos de afrontamiento y de búsqueda de bienestar (resiliencia). Por lo general, los programas que tratan el tema de la violencia se centran solamente en dimensiones del comportamiento disfuncionales o consideradas negativas, entre ellas la conducta delictiva, la deserción escolar o el embarazo adolescente. Nuestro enfoque de resiliencia, sin embargo, desea también documentar los comportamientos funcionales y considerados positivos a través de los cuales buscan su bienestar en contextos de adversidad. A ésto llamamos "resiliencia."

Aunque la normativa internacional ha promovido un enfoque holístico en los planes nacionales, las actividades en materia de violencia juvenil todavía se dividen según el tipo de violencia (política, territorial, del crimen organizado y doméstica, entre otros). Más notable aún, es la falta de un enfoque de las oportunidades, valores, afrontamientos positivos y otros recursos que también existen en contextos de adversidad, los cuales se pueden orientar hacia las respuestas institucionales. Los proyectos que se estructuran sólo en una perspectiva de carencia, riesgos y de patologías carecen de enfoques interrelacionados con las fortalezas existentes aún en contextos difíciles para reforzarse mutuamente. Finalmente, la falta

\footnotetext{
${ }^{2}$ El CYRM-28 es un instrumento de medición de resiliencia de niños, niñas y jóvenes desarrollado por el Centro de Investigación de Resiliencia en Canadá (por sus siglas en inglés, Child and Youth Resilience Measure o Escala de Resiliencia Juvenil y de la Niñez; vea Ungar y Liebenberg 2011).
}

<Paradigma> - Revista de Investigación Educativa. Año 21. No. 34 
de un marco conceptual integrado de disciplinas (salud pública, criminología, sociología y psicología, entre otras) es uno de los mayores obstáculos para alcanzar un tratamiento integral de la violencia (Moser 1999).

Las respuestas a la encuesta realizada por la CEPAL (2008) sobre políticas y programas de control y prevención de la violencia juvenil sugieren la coexistencia y competencia de diversos enfoques vinculados al papel y las necesidades del sujeto joven en América Latina. Se han establecido dos grandes enfoques de prevención de la violencia juvenil: uno centrado en la disminución de los factores de riesgo y otro en el fortalecimiento de los factores de protección y las fortalezas del adolescente. Esos modelos de prevención se han traducido en distintas líneas de acción para reducir la violencia juvenil, los cuales han servido de marco conceptual para este estudio.

\subsection{El concepto de factores de riesgo}

Paradigmas de violencia y riesgo: La vulnerabilidad juvenil entendida desde la perspectiva del riesgo psicosocial

La perspectiva del riesgo psicosocial posibilita analizar tanto las características del entorno inmediato o distante como las características personales que aumentan la probabilidad de que los jóvenes manifiesten dificultades en su desarrollo. También permite estudiar el modo en que diversas variables, (entre ellas la influencia de los pares, las características de la familia, la comunidad y la cultura) interactúan con vulnerabilidades individuales (por ejemplo las características cognitivas, temperamentales), sensibilizando a las personas ante ciertos riesgos (Trudel y Puentes-Neumann 2000). Debido a ello, este enfoque enfatiza la necesidad de analizar la forma en que diversos factores de riesgo interactúan en la generación de fenómenos como la delincuencia protagonizada por jóvenes.

Los factores de riesgo son variables que pueden afectar negativamente el desarrollo de las personas. En términos más específicos, cuando se habla de factores de riesgo se hace referencia a la presencia de situaciones contextuales o personales que, al estar presentes, incrementan la probabilidad de desarrollar problemas 
emocionales, conductuales o de salud. Estos problemas promueven la ocurrencia de desajustes adaptativos que dificultarían el logro del desarrollo esperado para el joven en cuanto a su transición de niño o niña a adulto responsable y capaz de contribuir y participar activamente en la sociedad. El desarrollo de los individuos no se da en forma aislada, ya que viven y se relacionan con una compleja red de sistemas interconectados, como la escuela, la familia, los grupos de pares y otras instituciones o situaciones que influyen en forma directa o indirecta en el desarrollo de las personas, y cuyas características pueden convertirse tanto en factores protectores como de riesgo. Es así como actualmente se considera la situación de "estar en riesgo psicosocial" como un estado complejo, que es definido por la intervención de múltiples situaciones.

Los factores de riesgo pueden ser clasificados en varios ámbitos de procedencia, de acuerdo a un continuo que va desde el nivel individual hasta el nivel sociocultural:

a) Factores individuales: Bajo coeficiente intelectual, pobre capacidad de resolución de conflictos, actitudes y valores favorables hacia conductas de riesgo, hiperactividad, temperamento difícil en la infancia. Los estudios recientes en el campo de la psicología del desarrollo sobre el papel que la agresión infantil desempeña en la violencia en la adolescencia, informan que los programas de prevención deben ajustarse a las necesidades de cada etapa del ciclo de desarrollo. Estos descubrimientos han suministrado bases para el planeamiento de programas de prevención que procuran capacitar a los niños y niñas para el relacionamiento social.

b) Factores familiares: La baja cohesión familiar, tener padres de familia con enfermedad mental, estilos parentales coercitivos, ambivalentes o permisivos. El papel de la familia continúa siendo crítico para garantizar mejores condiciones para los hijos, ya sea en la promoción del desarrollo saludable, ya en la prevención de la violencia, como víctimas o como agresores. Las investigaciones longitudinales han reiterado que a pesar de los cambios que se han dado en las estructuras y roles familiares en los últimos tiempos, del papel de los medios y del grupo de pares, los padres de familia siguen teniendo una fuerte influencia 
Zoila Suyapa Padilla

sobre el comportamiento de los hijos. Casi todas las familias tienen aspectos positivos que pueden ser usados como fundamentos para proteger a los niños, niñas y jóvenes de los riesgos. Cualquiera que sea el modelo de trayectoria del desarrollo de la violencia juvenil ("developmental pathways") que se adopte, la familia desempeña un papel primordial en estas trayectorias. Si la familia está en la raíz de problemas como el comportamiento antisocial, el abuso de drogas, el comportamiento sexual de alto riesgo y el fracaso escolar, ésta también tiene un papel destacado en la protección de los jóvenes.

c) Factores ligados al grupo de pares: Pertenencia a grupos de pares involucrados en actividades riesgosas (comportamiento delictivo, consumo de drogas, por ej emplo). Las investigaciones muestran que los vínculos con los grupos de pares y la imagenpercepción comienzan a formarse ya en el período preescolar y, al llegar a la escuela secundaria, tanto las imágenes como los vínculos ya están consolidados. Esto significa que las intervenciones con los grupos de pares deben ser tempranas, pues mientras mayor sea la edad, mayor será la influencia del grupo de pares, y, dado que los niños y niñas agresivos tienden a tener relaciones de amistad con otros niños y niñas agresivos, estos tienden a retroalimentar la agresión. Esta atracción mutua sucede porque es más fácil para estos niños y niñas imitar un modelo de comportamiento que tiene mayores probabilidades de refuerzo inmediato, que se percibe como semej ante al propio. O sea, es posible que los niños y niñas que tienen un comportamiento prosocial no puedan servir como modelos eficaces para los niños y niñas agresivos si no se establece desde temprano esta relación.

d) Factores escolares: Bajo apoyo del profesor, alienación escolar, violencia escolar. Tradicionalmente, Ias escuelas han sido el lugar privilegiado de las actividades de prevención por el hecho de reunir a un gran número de jóvenes, niños y niñas durante largos períodos del día, o sea, una población en un período de su desarrollo, teóricamente, de apertura al cambio. A pesar de la abundante presencia de programas de prevención en las escuelas, la gran mayoría de éstas no utiliza programas de eficacia comprobada. Parte de esto tiene que ver con la forma en que estos programas son introducidos a las escuelas y con los costos 
de los programas: el costo de los manuales, del entrenamiento de los equipos, su supervisión y la complejidad de los programas (Schaeffer et al. 2005; Evans y Weist 2004). Una vez que el sistema educativo ha hecho una inversión inicial en todos estos componentes, los responsables se resisten a reemplazarlos por otros. Las intervenciones de prevención en las escuelas abarcan una diversidad de tratamientos y de públicos, y tienen como objetivo prevenir distintos tipos de comportamientos problemáticos. Hay intervenciones que se dirigen sólo a los alumnos, otras a los alumnos y sus profesores, y otras que buscan cambiar el ambiente de la escuela, incluso con intervenciones en el espacio físico. Hay intervenciones que buscan informar a los jóvenes sobre los riesgos de algunos comportamientos, otras buscan cambiar valores y actitudes, otras son programas de aprendizaje socioemocional y otras buscan cambiar el comportamiento de los jóvenes dándoles nuevas alternativas para administrar situaciones de riesgo. A esta agenda se viene agregando un tema nuevo: enseñar a los niños y niñas a interactuar con sus compañeros de manera respetuosa y saludable, a contribuir con la comunidad, la familia y los compañeros; o sea, a tener algunas competencias sociales.

e) Factores sociales o comunitarios: Bajo apoyo comunitario, estigmatización y exclusión de actividades comunitarias. La comunidad puede ser un lugar de protección o de riesgo para los jóvenes: la capacidad de la comunidad para proteger está asociada a la presencia o ausencia de capital social. Las comunidades que poseen capital social de protección contra la violencia son aquellas en las que los adultos están dispuestos a proteger a los niños, niñas y a los jóvenes de la exposición a comportamientos de riesgo. Sucede que en las comunidades donde hay violencia, a menudo este capital social, si existe, no se ejerce; en estas comunidades, la protección que la familia ofrece puede no contrabalancear los riesgos, pues hay características sociales, físicas y económicas del barrio que afectan la salud y la calidad de vida al definir las oportunidades de acceso que los residentes tienen a las escuelas, a bienes y a servicios públicos. La existencia de estas comunidades de alto riesgo para niños, niñas y jóvenes alentó el desarrollo de programas de prevención destinados a la promoción de cambios 
en las condiciones de vivienda de las familias.

Hay mucha más violencia que afecta a jóvenes y niños en la comunidad que en las escuelas; sin embargo, hay muchos más programas de prevención de violencia desarrollados para ser aplicados en escuelas, experimentalmente evaluados e implementados, que en las comunidades. Catalano, Loerber y McKinney (1999) hicieron una revisión de los programas de prevención de la violencia que involucran a las comunidades y a las escuelas, para identificar cuáles son los programas eficaces, y examinaron cinco tipos de intervención: juegos estructurados en salas o patios de juego, trabaj o corporal, monitoreo y refuerzo de comportamientos, detectores de metales (en las escuelas), y amplia reorganización de la escuela.

f) Factores socioeconómicos y culturales: Vivir en condición de pobreza. La participación y la integración social han surgido como factores relevantes en el tema de la violencia juvenil. Las condiciones económicas, sociales y culturales deprivadas, restringen las posibilidades de conocer y adquirir saberes, tener acceso a fuentes diversas de información y contar con las redes de sostén para una formación integral. En un estudio realizado por la Universidad de Artes y Ciencias Sociales de Chile, se encontró que los factores socioeconómicos y culturales no solamente abarcan aspectos como el trabajo y la economía familiar sino que aluden a la construcción de los lazos sociales de los adolescentes y a la construcción de la identidad ciudadana que debe darse en esta etapa de su vida (Blanco et al, 2006).

Es importante entender los factores de riesgos que enfrentan los jóvenes en cada uno de los niveles explicitados en esta sección (individual, familiar, pares, escolar, sociales/ comunitarios y socioeconómicos culturales). Sin embargo, los estudios de resiliencia proponen igualmente estudiar, entender y proteger los factores de afrontamiento y de búsqueda de bienestar en contextos difíciles. Esta manera de entender la reacción de los jóvenes ante la adversidad se detalla a continuación. 
Resiliencia educativa de estudiantes ante los riesgos sociales generados por la barras juveniles de fútbol en Honduras

\subsection{La Resiliencia como una nueva forma de entender la reacción ante la adversidad}

La Resiliencia como el proceso de búsqueda del bienestar en cara a la adversidad

La aceleración de los cambios, producto de la modernización y la globalización, demanda nuevas estrategias de afrontamiento frente a la multiplicidad de orígenes y manifestaciones de factores adversos. Al avanzar los estudios se ha ido descubriendo que estos factores coexisten, interactúan y son mediados por una gran variedad de otras condiciones, tanto internas como externas a la persona, que intervienen en la cadena causal del desarrollo de los comportamientos violentos (Blum 1997). La cognición, el concepto propio, el autocontrol, la conexión con otros y la capacidad de establecer compromisos al ser activados por oportunidades presentes en el contexto, llegan a influir en la dirección e intensidad de las respuestas de la persona ante situaciones de adversidad (Reyes, 2013). Este paradigma ha sido estudiado baj o el concepto de Resiliencia y resulta atribuible tanto a individuos como a comunidades (Ungar et al. 2007).

La Resiliencia se ha caracterizado como un conjunto de procesos sociales y personales que posibilitan tener una vida sana aun viviendo en un medio insano. Estos procesos tendrían lugar a través del tiempo dando combinaciones positivas entre atributos del niño 0 niña y su ambiente familiar, social y cultural. Significa entonces que la Resiliencia se adquiere durante el desarrollo de las etapas de vida de una persona y se puede o no fortalecer, dependiendo de las condiciones individuales en relación con condiciones dadas en un contexto determinado. Benard (2004) Ilama a esta competencia resiliencia humana, y la define como la capacidad universal de todos los individuos (no sólo algunos) en contextos de adversidad de encontrar sentido y propósito; de un manejo afectivo a sí mismo y con otros; de desarrollar destrezas eficaces, conexión social, y autonomía, al igual que de manejar los constantes cambios.

En este proceso se pone en juego el concepto propio y emocional (búsqueda de regulación interna) ya que la adversidad "engancha" 
nuestras emociones y brinda oportunidad de manejo (del enojo, del duelo/dolor, de la esperanza, de la empatía, del humor, de la relajación) y nos ayuda a desarrollar el auto-conocimiento, la autoestima, y la confianza en uno mismo (Masten y Obradovic 2006).

Resiliencia individual, resiliencia familiar y resiliencia comunitaria

El énfasis en la resiliencia individual llevó a los clínicos a tratar de atender solamente a los sobrevivientes en forma individual sin analizar las potencialidades de su familia, o incluso a expensas de dar por perdida a ésta o considerarla impotente. Sin embargo el concepto de resiliencia familiar reafirma la capacidad de auto reparación de la propia familia y ayuda a identificar y fomentar ciertos procesos que permiten a éstas hacer frente con más eficacia a las crisis o estados persistentes de estrés, sean internos o externos, y emerger fortalecidas de ellos. Walsh (1996) entiende que la familia es un foco de resiliencia pese a situaciones de alta disfuncionalidad y que al consolidar la resiliencia familiar, robustecemos a la familia como unidad funcional y posibilitamos que inculque esa capacidad en todos sus miembros. Se ha demostrado, que para evaluar el funcionamiento individual y familiar sano importan más los procesos que la forma de la familia, lo que incluyen como el ementos básicos de la resiliencia los procesos de cohesión, flexibilidad, comunicación franca, resolución de problemas y reafirmación del sistema de creencias (Walsh 1996). También estos elementos han sido importantes para el examen de los procesos de transición ante cualquier situación de crisis.

En la comunidad, los individuos comparten espacios y servicios en común y actúan recíprocamente, lo cual propicia la oportunidad de adquirir atributos propios de la resiliencia. Las comunidades son resilientes cuando al responder a situaciones adversas como las crisis económicas y medioambientales, entre otras, cuentan con recursos y capacidades que las fortalecen. Entre los factores de resiliencia comunitaria figuran la cultura, las oportunidades de socialización en forma segura, el apoyo mutuo, las expectativas colectivas de éxito ante los desafíos y una actitud predominantemente optimista, el trabajo voluntario, así como un alto nivel de participación. En su desarrollo teórico y aplicativo, se 
ha ido acercando a la concepción de comunidades saludables y al tema de capital social (Suárez Ojeda y Krauskopf 1995).

Resiliencia y las Respuestas Institucionales Ante la Adversidad

La perspectiva de resiliencia no implica dejar solos a los individuos y a las comunidades a afrontar sus riesgos. Al contrario, las instituciones de la sociedad son llamadas a proveer servicios y oportunidades para los más vulnerables (Ungar 2005). A este tipo de Resiliencia se le llama resiliencia transformativa, definiéndose como la capacidad de una sociedad determinada de cambiar la adversidad y las amenazas en oportunidades de transformación positiva (Valikangas 2010). Desde esta mirada la resiliencia se entiende como un fenómeno contextualizado. Es decir que los efectos, comportamientos y significados tanto de la adversidad como del éxito, el riesgo y la protección deben ser identificados localmente, con base a cada contexto cultural y social.

Podemos identificar que existe resiliencia transformativa 0 transformadora en una sociedad cuando se presentan los indicadores siguientes (Ungar y Lieberman 2011) de oportunidades y servicios públicos para los más vulnerables:

a) Existe contribución-en un esfuerzo nacional y multisectorialpara mitigar y prevenir la violencia.

b) Existe intención explícita del estado y la sociedad para transformar la sociedad desde las raíces de la violencia aprovechando las raíces de las fortalezas nacionales.

c) Se evidencia un esfuerzo nacional para identificar las raíces causales de la violencia y de los recursos de Fortaleza socialapoyado por los investigadores, los medios, actividades comunitarias, etc.

e) Existe una planificación, programas y recursos nacionales y multisectoriales con el objetivo explícito de mitigar la violencia y fomentar las fortalezas de las comunidades.

f) Se da cohesión y movilización social, empoderadora y que conecte a la sociedad en su totalidad (sin diferencias ni exclusiones) -a través de marchas por la paz, debates, y otros movimientos sociales empoderadores. 


\subsection{El papel del sector educativo}

La propuesta de "resiliencia transformadora" nos lleva directamente hacia el papel del sector educativo para proteger a la niñez y juventud más vulnerable ante las adversidades, incluyendo la violencia. Las escuelas continúan siendo, a pesar de todas las transformaciones por las que han transitado, uno de los ámbitos de socialización más importantes, al mismo tiempo que constituyen un espacio donde los jóvenes pueden tener oportunidades de desarrollo personal más allá de sus entornos y de las condiciones sociales en que se desenvuelven. La necesidad de fomentar la convivencia democrática y la formación ciudadana de los niños, niñas y jóvenes son fuertes razones que han impulsado en los últimos años la reflexión, el debate, la investigación y la elaboración de nuevas propuestas educativas sobre la Educación. Para la UNESCO, la escuela requiere de la convivencia como condición indispensable para lograr aprendizajes, como lo establecen claramente los resultados del Segundo Estudio de Factores del Laboratorio Latinoamericano de Calidad de la Educación (SERCE del LLECE) de la OREALC/ UNESCO. En ellos se determinó una asociación de entre el 20 y el $50 \%$ entre logro de los aprendizaj es y el denominado "clima escolar" (UNESCO/ OREALC 2008). Con el incremento de los factores de riesgo en el ámbito social y particularmente en el educativo ha surgido la necesidad de revisar el rol que juega la escuela en la generación, prevención o mitigación de fenómenos sociales como la violencia.

Un estudio de Walsh y colaboradores (1999), analiza-y eventualmente refuta-la hipótesis habitual y de sentido común que enuncia que las comunidades "problemáticas" o "violentas" producen inevitablemente alumnos o escuelas "problemáticas" o "violentas". Los autores descomponen analíticamente la noción de conflictividad escolar y dividen los factores que contribuirían a su emergencia y mantenimiento en tres niveles lógicamente superpuestos: individual (psicológico), institucional (escolar) y comunal (social). Luego de un riguroso proceso de análisis estadístico concluyen que son los factores institucionales, fundamentalmente los relacionados con el "clima escolar", los principales responsables del "desorden" y la conflictividad que puedan observarse en una escuela determinada. Así, enumeran una serie de factores que contribuyen a aumentar el "desorden" escolar, en particular la inconsistencia por parte de los 
Resiliencia educativa de estudiantes ante los riesgos sociales

docentes o directivos, la falta de claridad o arbitrariedad en las reglas 0 en su aplicación, las operaciones ambiguas o indirectas ante la inconducta (por ejemplo, utilizar las calificaciones como sanción ante la conducta problemática), el desacuerdo entre los actores del sistema escolar en cuanto a la existencia, el contenido o la aplicación de las normas, la falta de respuestas a la conducta problemática persistente, la irrelevancia de las normas desde el punto de vista de los alumnos, la existencia de relaciones conflictivas entre docentes y directivos, una dirección inactiva o ausente, bajos recursos y tamaño (expresado en la tasa de alumnos por docente). Idénticos objetivos-aunque con una metodología analítica más sofisticada-se proponen el estudio de Benbenishty y Astor (2008) para las escuelas israelíes, basado en la CSCSS (California School Climate and Safety Survey). A partir de la construcción inductiva de las categorías de análisis, los autores encuentran que diversas formas de comportamientos violentos pueden asociarse a diversos dominios causales. Así, los resultados muestran que las formas más extremas de violencia sí estarían asociadas al entorno social inmediato de las escuelas, mientras que las formas de violencia leves y moderadas, así como la violencia que ellos denominan "social verbal" registran fuertes niveles de asociación con el clima institucional del establecimiento bajo análisis. Asimismo, uno de los puntos más demostrados por otros estudios es la asociación entre las manifestaciones de violencia y el clima social escolar, entendido como "las percepciones que tienen las personas acerca de las relaciones interpersonales que establecen en el contexto escolar y el contexto o marco en el cual estas interacciones se dan" (Kornblit 2000). Los estudios encuentran dos variables que caracterizan dominios considerados definitorios en relación con la construcción del clima social en las escuelas: la relación docente-alumno (incluyendo el grado potencial de autoritarismo implicado en la relación) y el sentimiento de pertenencia (por oposición al individualismo y aislamiento).

Considerando estos estudios, puede concluirse que el análisis de los climas escolares resulta crucial para la comprensión de la naturaleza, dimensiones y lógica del fenómeno de la violencia en las escuelas y sus efectos en la formación de los futuros ciudadanos. Asimismo, permite tomar distancia de la mayor parte de las explicaciones deterministas, ya sean psicológicas (la violencia como producto de 
personalidades "desviadas" producidas en otro sitio) o sociológicas (la violencia como producto inevitable de condiciones sociales externas a la institución escolar), abriendo el camino a la posibilidad de intervención de la institución escolar en relación con sus dinámicas internas de conflicto y agresión.

Figura 1.

Las múltiplesfacetas de la educación en contextos frágiles y de conflicto (The Multiple Faces of Educaton in Conflict and Fragile Contexts).

\section{El papel del sector educativo frente a la violencia y conflicto}

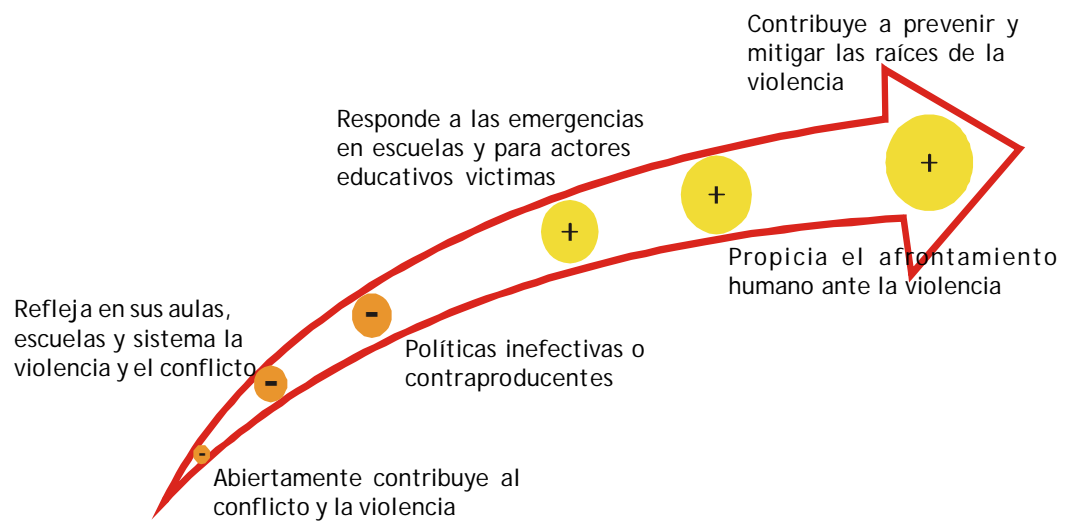

Fuente: Adaptado por la Red Internacional para la Educación en Situaciones de Emergencia (INEE) (2012)

El pensamiento y la disposición positiva, por parte del profesorado, son claves esenciales a la hora de promover resiliencia en el alumnado, en la medida en que facilita y ayuda a superar contrariedades, percibirlas dificultades como retos y estimula hacia las metas propuestas.

La Rueda de la Resiliencia (Henderson y Milstein 2003), es un diagrama muy ilustrativo que recoge los pasos necesarios para promover resiliencia en el contexto escolar: 
Figura 2.

La Rueda de la Resiliencia

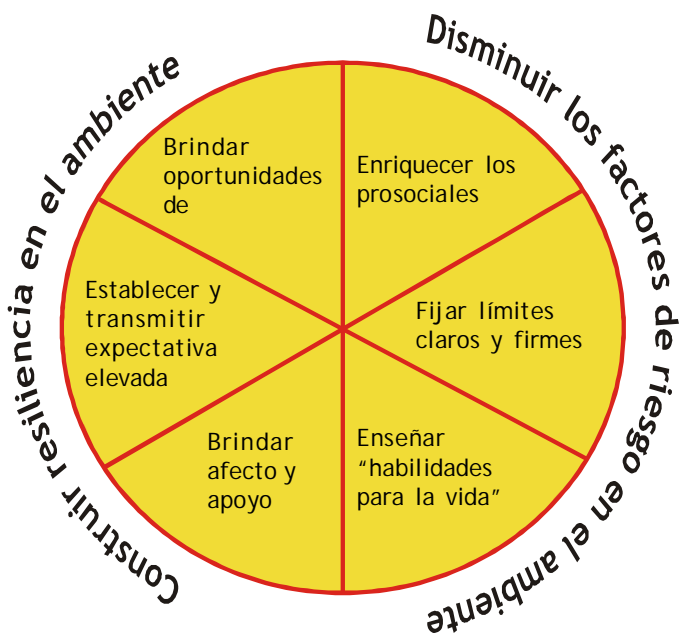

Fuente: Henderson y Milstein 2003

Habiendo integrado los tres elementos para un estudio de resiliencia educativa - riesgos, fortal ezas y respuesta institucional-pasamos al análisis de dos estudios de caso enfocados en el fenómeno de barras juveniles en los centros educativos de Honduras. Entender mejor los riesgos que enfrentan estos jóvenes, pero también sus maneras de afrontamiento positivas, esperamos pueda guiar una respuesta más relevante del sector educativo tanto de protección (de los riesgos) como de fomento (de los factores de resiliencia).

\section{Punto de partida de los estudios de caso}

El marco conceptual del estudio del capítulo anterior presentó tres pilares básicos para un estudio de resiliencia educativa: (i) la necesidad de entender los riesgos que enfrentan los estudiantes (niñez y juventud) en Honduras; (ii) el valor agregado de entender igualmente la resiliencia-o afrontamientos positivos de los estudiantes ante la violencia; y (iii) el imperativo de la respuesta institucional del sector educativo ante tales riesgos y oportunidades. Con base en este marco conceptual, se llevaron a cabo dos estudios de caso para entender mejor los riesgos que enfrentan los estudiantes en los centros educativos de secundaria en Honduras, 
especialmente frente a la violencia que generan las barras de fútbol dentro de las instituciones educativas. Desde una perspectiva de resiliencia, se hecho énfasis en la búsqueda de bienestar por parte de estos jóvenes, sus comportamientos y valores positivos, y las oportunidades que se le presentan para evadir los riesgos. Este capítulo amplia el contexto educativo de Honduras donde están situados los dos estudios de caso, al igual que el contexto específico de cada uno de ellos.

\subsection{Contexto educativo y social del país}

Según la Encuesta Permanente de Hogares de Propósitos Múltiples del año 2008 (INE) en Honduras, hay 2,976, 918 jóvenes entre 12 y 30 años, lo que representa el $38.7 \%$ del total de la población. Honduras invierte el $7.2 \%$ del PIB en educación. Sin embargo, un poco más del $80 \%$ del presupuesto asignado a la Secretaria de Educación, se invierte en sueldos y salarios. Según datos de 2008, el $94.2 \%$ de Ios/ las jóvenes han cursado la educación primaria, $45.7 \%$ educación secundaria y el $6.7 \%$ educación superior. Las mujeres jóvenes superan a los hombres jóvenes en educación primaria, media y superior.

El aumento del acceso a la educación y la tecnología es profundamente desigual. Los jóvenes de zonas pobres y rurales cuentan con menores posibilidades de acceder a una educación digna respecto a los jóvenes de zonas urbanas y capas medias, medias altas. A nivel Universitario únicamente el $0.5 \%$ de jóvenes de hogares de ingresos bajos está cursando la universidad, en tanto que este porcentaje sube a $25.2 \%$ en el caso de jóvenes de hogares con ingresos altos. En Honduras la educación secundaria no es obligatoria. Hasta ahora con la Ley Fundamental de Educación extienden la obligatoriedad hasta el noveno grado.

Según la Trigésima Novena Encuesta Permanente de Hogares de Propósitos Múltiples del año 2010, la tasa de analfabetismo alcanza el $15 \%$ en el país. 
Gráfica 2:

Tasa de analfabetismo

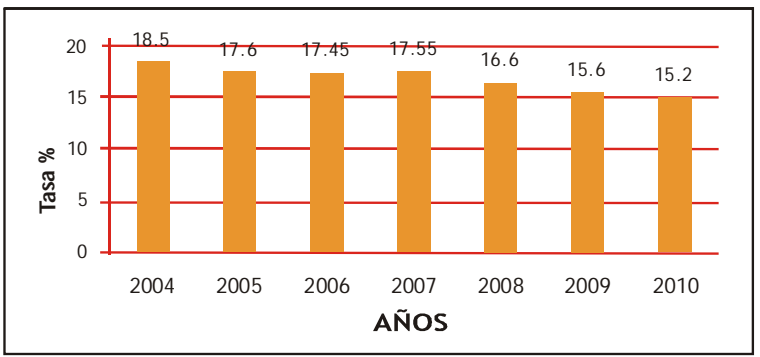

Fuente: INE, XXXIX Encuesta Permanente de Hogares de Propósitos Múltiples (2010)

\subsection{Contexto educativo y social de los Centros educativos participantes}

\section{Instituto Central Vicente Cáceres}

El Instituto está localizado en la capital del país. Su población de egresados sobrepasa los 100,000 y presenta una matrícula total para 2012 de 6,994 estudiantes en ambos sexos atendidos en las diferentes modalidades de estudio. De la población estudiantil antes mencionada, 721 son de III curso de Ciclo Común de Cultura General atendidos en la jornada matutina, los cuales son de interés para nuestro estudio. Este instituto de educación secundaria está ubicado en una zona céntrica de la capital de Honduras, y está circundado por centros comerciales, barrios marginales y áreas de alto tránsito peatonal y vehicular.

Tabla 1

Total de matrícula consolidada del Instituto Central Vicente Cáceres, Año 2011

\begin{tabular}{|c|l|c|c|c|}
\hline \multicolumn{2}{|c|}{ Forma de entrega de servicios } & Femenino & Masculino & Total \\
\hline 1 & Presencial & 2674 & 2056 & 4730 \\
\hline \multicolumn{5}{|l|}{} \\
\hline 2 & ISEgramas alternativos & 1144 & 650 & 1794 \\
\hline 3 & SAT & 0 & 0 & 0 \\
\hline 4 & IHER & 0 & 0 & 0 \\
\hline
\end{tabular}

Fuente: Secretaria de Educación de Honduras, Portal de Estadísticas. http:// estadísticas.se.gob.hn, visitado en 2012 
Zoila Suyapa Padilla

Nota: El ISEMED son los Institutos del Sistema de Educación Media a Distancia; EI SAT es el Sistema de Aprendizaj e Tutorial; el IHER es el Instituto Hondureño de Educación por Radio.

Como se evidencia en el cuadro anterior, el Instituto Central ofrece todas las modalidades de estudio para atender las necesidades de cada grupo estudiantil: estudiantes de tiempo completo, estudiantes que trabajan, estudiantes que requieren de un programa más condensado. Esta diversidad de oferta para una población tan grande, constituye tanto una oportunidad como un reto para la convivencia. Los intereses de cada grupo exigen al cuerpo docente y directivo una gestión académica efectiva, lo que se logra con un manejo muy organizado de los diferentes quehaceres de la institución. Desde su origen, el Instituto Central ha recibido el apoyo de organizaciones gubernamentales y no gubernamentales para el desarrollo estudiantil. Además, es un centro de práctica de la Universidad Pedagógica Nacional lo que garantiza una relación con la fuente de formación de maes-tros del país y el intercambio de experiencias en materia docente.

El incremento de la crisis social en el medio circundante, permea la vida estudiantil y no son pocos los episodios de violencia que se viven. Esto ha sido una lucha desde que se formaron en el Central las primeras pandillas de jóvenes, que en principio, estaban formadas solamente por mujeres. Como ya se indicó, por su ubicación social y geográfica, este centro educativo se encuentra rodeado de un sector poblacional que habitan en colonias de clase media-baja, además de ser una zona de alta actividad comercial en donde se pueden identificar negocios que forman parte de la economía formal, en este caso establecimientos comerciales y negocios informales como ventas ambulantes. Así mismo se encuentran oficinas de gobierno y una posta policial. Frente al centro educativo se encuentra una de las estaciones de buses más utilizadas por la misma población estudiantil, sobre todo en horas en donde los estudiantes se dirigen a desarrollar sus actividades académicas o terminan las mismas. Asimismo frente al centro educativo se ubica una arteria vial principal que comunica la capital con el norte del país. Este panorama nos muestra un escenario muy propicio para la manifestación de diversos factores de riesgo sobre los que se necesita una política de 
manejo permanente y que hasta ahora, no se encuentra articulada.

Para este estudio de Resiliencia se ha considerado una muestra de estudiantes que cursan el noveno grado de Educación Básica. Tomando como criterio de selección:

a) la edad

b) el cierre de su tercer ciclo de formación

c) la pronto toma de decisión de su formación profesional de educación media.

\section{Centro de Educación Básica Ricardo Soriano}

A consecuencia del fenómeno natural huracán Mitch que azotó Honduras en 1998, esta institución fue reubicada en el año 1999 en un terreno de Ciudad Nueva donado por la Alcaldía Municipal. En esta zona, se pueden identificar unas 10 Colonias habitacionales y es el punto de cruce de la Carretera Internacional, la cual se constituye en vía de comunicación fronteriza entre Honduras y Nicaragua. Esta zona ha sido catalogada como de alto riesgo por su exposición al tráfico de personas, drogas y armas, entre otros. Asimismo la población estudiantil está expuesta a padillas o maras, ya que está ubicado en un territorio disputado por pandillas juveniles, como se evidencia en las marcas de calles y casas.

En el 2000, se convierte de escuela completa de 6 grados, a un Centro de Educación Básica de 9 grados. En sus inicios la infraestructura física fue de materiales prefabricados, posteriormente siete aulas de ladrillo y techo de tej a. Actualmente, se cuenta con trece aulas de clase incluida un aula taller y de computación donde se atiende una matrícula de más de 1000 estudiantes, de primero a noveno grado, distribuidos en dos jornadas. El personal administrativo está compuesto por una Directora, Subdirectora, Secretaria, una Consej era, una Orientadora, dos Bibliotecarias, dos Maes-tros de Infotecnología, y 23 docentes a cargo de los nueve grados.

Resulta evidente el esfuerzo del personal docente y directivo por mantener un ambiente apropiado para la educación de los jóvenes. 
Con muchos esfuerzos, se han ido mejorando las instalaciones físicas y el equipamiento básico para aulas y talleres. También se estimula la participación en equipos deportivos y artísticos. Una gran lucha que mantiene el centro, es por completar el cerco perimetral, lo que resulta urgente para la seguridad de los estudiantes y profesores.

Tabla 2

Matrícula consolidada del Instituto Ricardo Soriando, Año 2011

\begin{tabular}{|c|l|c|}
\hline \multicolumn{2}{|l|}{$\mathbf{1}$ a $\mathbf{6}$ grado (1 y 2 ciclos) } & Total \\
\hline 1 & Femenino & 306 \\
\hline 2 & Masculino & 338 \\
\hline \multicolumn{2}{|l|}{ Subtotal } & 644 \\
\hline $\mathbf{7}$ a $\mathbf{9}$ grado (3 ciclo) & 156 \\
\hline 1 & Femenino & 147 \\
\hline 2 & Masculino & 303 \\
\hline \multicolumn{2}{|l|}{ Tubtotal } & 947 \\
\hline \multicolumn{2}{|l|}{ matrícula } & \\
\hline
\end{tabular}

Fuente: Secretaria de Educación de Honduras, Portal de Estadísticas. http:// estadísticas.se.gob.hn, visitado en 2012

Considerando para este estudio los mismos criterios de muestra que se seleccionaron en el Instituto Central Vicente Cáceres, tanto en edad, nivel de escolaridad y características específicas por el nivel educativo que cursan.

Los dos estudios de caso-el Instituto Central Vicente Cáceres y el Instituto Ricardo Soriano -han permitido documentar los riesgos ante la violencia que se viven aun dentro de los planteles educativos. Sin embargo, desde una perspectiva de resiliencia, también se han documentado la búsqueda de bienestar de los jóvenes, y sus comportamientos y valores positivos que muchas veces se pierden de vista ante tanta adversidad. El Capítulo III amplía los hallazgos en torno a los riesgos, y el Capítulo IV se enfoca en los comportamientos y oportunidades positivas ante el proceso de resiliencia de los jóvenes en estos institutos y los otros actores alrededor que igualmente buscan el bienestar de los estudiantes. 
Resiliencia educativa de estudiantes ante los riesgos sociales generados por la barras juveniles de fútbol en Honduras

\section{Hallazgos del estudio: Violencia y riesgos}

En los dos estudios de caso, los riesgos que afectan a los estudiantes denotan una creciente ola de violencia. Dicha violencia refleja claramente la violencia que vive el país. Este capítulo, por lo tanto, presenta este panorama no para estigmatizar a los jóvenes que enfrentan estos riesgos, sino para un llamado de alerta a nivel institucional y político. La violencia no se vive solamente en las calles; también afecta a los centros educativos. Sin embargo, como se presenta en el Informe Final, los estudiantes en los centros escolares participantes de este estudio, presentan una riqueza de estrategias positivas de afrontamiento hacia la violencia, como parte de su propia búsqueda de bienestar.

\subsection{Desde la percepción de los Estudiantes}

Los estudiantes viven cotidianamente innumerables situaciones de riesgo como lo demuestran sus respuestas a las categorías detalladas a continuación. Su percepción de estas manifestaciones de la violencia en su entorno educativo, resulta muy importante para entender la dinámica sobre la que se desenvuelve su día a día escolar y, en consecuencia, desarrollar las acciones que sean necesarias para fortalecerlos en su capacidad de afrontamiento y protección frente a las diversas formas de violencia y particularmente, la generada por las barras juveniles de fútbol.

\section{a) Riesgos de mayor prevalencia}

Para los estudiantes participantes en el estudio, los mayores riesgos a que se ven expuestos (en orden descendente) son los asaltos, reclutamiento e intimidación por parte de maras 0 pandillas, involucrase en peleas y tener problemas sociales.

Asaltos y robos: L Asaltos y robos: La posibilidad de ser asaltados parece estar ya incorporada en el imaginario de los estudiantes como algo inevitable y cotidiano. Expresiones como "hay que prepararse para que a uno lo asalten", "es mej or andar con celulares baratos por si te lo roban" son parte de las conversaciones normales entre los estudiantes. La prevalencia de asaltos y robos reportada 
va desde un mínimo de tres hasta veintiséis veces para una misma persona.

Maras: La presencia de las maras la reportan con mucha claridad los estudiantes. Los símbolos y parafernalia de cada mara son fácilmente reconocidos, reforzados por el hecho de que éstos aparecen en el grafiti de aulas o en las paredes del edificio educativo. Según los estudiantes, el reclutamiento se inicia poco a poco a través de un emisario. El riesgo de no pertenecer a la mara puede llegar a situaciones extremas: “Varias jóvenes tienen que acceder a las peticiones de los mareros, que se infiltran como estudiantes, antes de perder la vida. Sólo denunciar las acciones de estos grupos representa la muerte y en vez de eso prefieren callar y ser parte de la estructura" (Diario La Prensa 2012).

Peleas: Las peleas forman parte del escenario frecuente en recreos y salidas de clase. Según los estudiantes, las peleas pueden llegar a niveles tan altos de agresividad que ni los guardias del centro educativo se atreven a intervenir. Para al gunos estudiantes, en ciertos casos, los guardias parecen estar confabulados para que se den las peleas en el centro.

Los riesgos percibidos como de menor prevalencia por parte de los estudiantes son los asesinatos, extorsiones, las agresiones de las barras de fútbol, las burlas.

Asesinatos: Aún cuando los estudiantes admiten que en el centro circulan armas, no perciben los asesinatos como un riesgo al que puedan verse sometidos. En efecto, las estadísticas de ambos col egios no reportan ningún incidente de este tipo en los últimos años al interior del plantel educativo, aunque si se reporta el decomiso de armas llamadas "hechizas" (de fabricación casera). Sin embargo, la mayoría señala que no ha sido golpeado o amenazado con arma (80\%).

Extorsiones: Son pocas las alusiones al riesgo de ser extorsionados, lo cual parece de alguna forma contradictorio con las estrategias de reclutamiento a maras, lo que sí es percibido como riesgo mayor. 
Barras de fútbol: Las barras de fútbol son percibidas como riesgo al igual que las maras. La afición al fútbol es casi total en la población estudiantil y aparece como señal de identidad nacional, lo que hace difícil para los estudiantes mantener la alerta ante el riesgo que pueden representar. Los medios de comunicación evidencian las manifestaciones violentas de las barras de fútbol dentro y fuera de los estadios, sus enfrentamientos con la policía y el temor que generan en la población, incidiendo de manera directa en la baja sensible de asistencia a los estadios (Proceso Digital 2013):

Los enfrentamientos que se han generado últimamente entre miembros de barras generan miedo y negativismo entre la población, lo que podría terminar de sepultar el fútbol profesional hondureño, que en los últimos años se encuentra en una profunda crisis ante los problemas económicos que enfrenta el país (Proceso Digital 2013).

Para los estudiantes los que se involucran "se meten en la barra porque no tiene apoyo de los padres de familia, no estudian, porque no tiene nada que hacer, no tienen trabajo, por eso están metidos en eso... algunos si están estudiando pero siempre se meten a la barra... en la barra se encuentran amigos", "ellos dicen que se meten a la barra para agarrar fama...". Esta ambivalencia de valores es la que atrae a muchos estudiantes, en una edad en la que el protagonismo y el afán de sentirse parte de un grupo que lo reconoce juegan un papel clave en la conformación de la personalidad.

Abuso sexual: En cuanto a prevalencia de abuso sexual, es de señalar que un $96 \%$ de los estudiantes encuestados expresa no haber sido lastimado sexualmente. Del $4 \%$ restante, un $0.2 \%$ señala haberlo sido más de 26 veces. Estos datos pueden indicar que aún cuando el problema de abuso sexual en ambos centros educativos no es masivo, por sus repercusiones, requiere especial atención cuando aparece, pues tiende a ser recurrente para la víctima, con efectos que pueden ser devastadores.

Involucración en pandillas: Sobre la involucración en pandillas, la mitad de los estudiantes reporta que tiene compañeros que están 
involucrados (50\%) en alguna pandilla. Este hecho se correlaciona con la prevalencia de maras como riesgo alto percibido por los estudiantes. Aun cuando la mayoría (79\%) reporta que ningún miembro de su familia está involucrado en pandillas existe un $26 \%$ que reporta que algún miembro de la familia ha pertenecido 0 pertenece a una pandilla, lo que sugiere que la vinculación en al gunos casos es de segunda generación, si consideramos que fue en los años noventa cuando se detectaron las primeras pandillas juveniles en el Colegio. Actualmente, según un estudio patrocinado por UNICEF las maras y pandillas están provocando la deserción de estudiantes de los centros educativos y, además, "tiene atemorizada a la población" (UNICEF 2012). Lo que se evidencia de estas respuestas es que la exposición a la cultura de las pandillas es alta, aún cuando no se esté directamente involucrado.

\section{Gráfico 1}

Riesgos a las que se ven expuestos los estudiantes

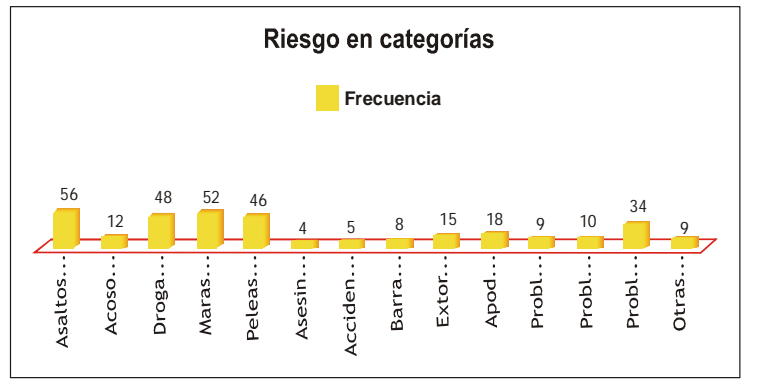

Fuente: Encuesta de Resiliencia Honduras 2012. Elaboración propia. Análisis Cuantitativo

\section{b) Lugar de mayor prevalencia de riesgos}

La comunidad, es decir el exterior del centro educativo, es el lugar de ocurrencia más señalado para que aparezcan los riesgos de acuerdo a la percepción de los estudiantes (38\%). En Segundo lugar se percibe el interior del Instituto (29\%) y en tercer lugar la familia (11\%). Pocos estudiantes señalan que es en múltiples lugares (5\%). Este hecho correlaciona con lo mencionado en los estudios de investigación en escenarios parecidos y lo reportado por las autoridades de ambos colegios. Sin embargo, contrasta con lo proclamado en los medios de comunicación de masas, quienes tienden a mostrar los centros educativos como escenarios muy violentos. 


\section{Gráfico 2}

Donde se encuentra el riesgo

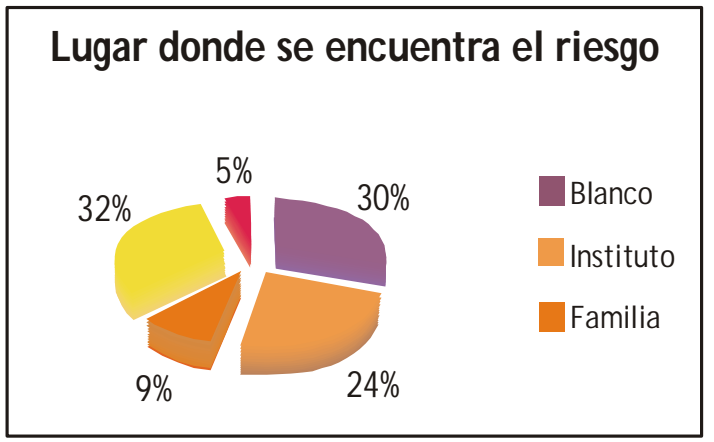

Fuente: Encuesta de Resiliencia Honduras 2012.

Elaboración propia. Análisis Cuantitativo

Por otra parte se encontró que los índices de violencia juvenil e involucración en barras y maras son mayores al exterior de los centros educativos. Se nota que, es difícil ponderar el nivel de prevalencia: "este... dentro de la institución... ya es considerable pero no pudiera medirla si es alta o media pero si ya es frecuente".

\subsection{Desde la percepción del personal de los Centros Educativos}

El equipo profesional de los centros educativos también señala, que en su formación como maestros recibieron algo sobre orientación y consej ería pero ninguna formación sobre violencia juvenil. Es sobre la marcha que han tenido que ir encontrando las estrategias para conocer el problema y usar las estrategias para atenderlo.

Los mayores riesgos a que se ven sometidos los estudiantes de acuerdo a la administración institucional son: influencias externas, consumo de drogas y alcohol, asaltos y robos, bajo rendimiento académico, relaciones sexuales precoces, reclutamiento por maras y la migración de los padres de familia a otros países.

Influencias externas (internet, juegos de video, TV): Para los administradores educativos, la influencia del internet y la televisión ha marcado un cambio en la conducta de los estudiantes. 
Me parece que las influencias negativas externas a la formación que se debe tener en casa en los hogares y en los centros educativos, son fuertes... mire, ellos pasan gran cantidad de tiempo frente a los televisores, frente a los juegos de video, frente el internet... hace algunos años cuando yo era adolescente, ahora yo tengo 45 años, estoy hablando aproximadamente de unos 30 años atrás eso no lo teníamos.

Esta aseveración se presenta por igual en ambos colegios, aún con la diferencia de acceso a internet y computadoras que podría haber entre la capital y la zona sur.

Consumo de drogas y alcohol: En la entrevista con el personal de la institución se relatan que "hay problemas de alcoholismo; de hecho tenemos unas pruebas decomisadas allí... botellas de ron plata, marihuana son de varones o de ambos sexos, pero la marihuana es más para varones". La circulación de la droga se da porque logran introducirla a pesar del registro de mochilas escolares a la entrada del centro, por lo que periódicamente se realizan "operativos" (registros imprevistos) para decomisarla. El consumo de alcohol y drogas en el país está abarcando edades más tempranas según el Instituto de Alcoholismo y Drogadicción, con un aumento de consumo visible por parte de las mujeres. Es de hacer notar que los estudiantes no reportaron este hecho como un riesgo percibido.

Asaltos y robos: Un administrador relató lo siguiente acerca de asaltos y robos dentro de la institución.

Debo decir, confesar con mucha pena, pero es una realidad. Pero como estamos teniendo esta situación de convulsión del país...debo decirle que la verdad aquí nuestros alumnos han sido asaltados en los pasillos con navaja en mano, les quitaban los tenis, les quitaban las mochilas, les quitaban el dinero... hasta la comida a los niños pequeños porque había gente que se infiltraba al centro, confabulados con la vigilancia en que estaba en ese momento. Por eso se cambió para mejorar la situación y esta situación se erradicó; aun así tenemos un nivel de violencia en el colegio que existe. 
Bajo rendimiento académico: El índice académico de los estudiantes es una preocupación para los administradores de los colegios, a lo que dedican gran parte de sus esfuerzos. Un dato que da uno de los entrevistados es que en el colegio que enseña el índice académico bajo se ubica entre un 35\% a un 65\% aunque en total logran pasar del $75 \%$ Las autoridades señalan que han tenido que aplicar medidas extraordinarias para subir el índice, como dar clases de reforzamiento y tutorías y han logrado subir la excelencia académica, sin embargo aún no logran llegar a lo esperado a nivel nacional. Las disposiciones de la Secretaría de Educación son muy fuertes cuando un centro educativo muestra índices bajos (existe un ranking de control), lo que explica la preocupación de los administrativos. Las áreas de Español y Matemáticas siguen con índices nacionales debajo del 50\% o 60\%y es el Tercer Ciclo ( 13 a 15 años de edad) donde se evidencian los rendimientos inferiores.

Relaciones sexuales precoces: Las relaciones sexuales en los centros educativos se dan desde edades tempranas. Según las autoridades "esos son sucesos que realmente me preocupan porque han ocurrido dentro de la institución y eso no debe darse". La actividad sexual es más penalizada socialmente en el caso de las mujeres, fortaleciendo en cierta manera un enfoque machista y un sesgo de género sobre la sexualidad. Los informes sobre pregnancia juvenil señalan que Honduras reporta un $37 \%$ de prevalencia, uno de los más altos de Centro América.

Reclutamiento por barras y maras: La violencia que se da al interior de los centros es percibida por los Directores como:

...provocada por personas que vienen de fuera a buscar los que están dentro. Me imagino que éstos que están dentro son simpatizantes de algunas de las barras entonces ellos se agrupan y ahí es donde se provoca la violencia.

Hablando sobre las barras relacionadas a equipos de futbol, éste es un problema más externo que interno.

Sabemos que los muchachos están divididos en [barras]. No se quieren, pero fíjese que no se da solo en el colegio, para serle 
franco no se refleja en el colegio se refleja más en los partidos los domingos que juegan [equipos].

Además se señala que la involucración en barras no es sólo de los varones. "Parece que sólo fueran varones pero hay muchas señoritas en estos grupos que se hacen llamar las 'bebas' y las 'potras' . La razón de esta involucración según algunos de los entrevistados, es la de:

El liderazgo, no es el fútbol, es controlar a las otras, es cuestión de ego digo yo, de sentirse poderosas sobre las demás. Se constituyen grupos en más pensando en que yo soy la que mando y yo soy la que controlo, de hecho es de sentirse con sentido de pertenecía al mismo equipo, es bastante grande.

En un estudio realizado por la UNESCO en 2008 se plantea que las "Pandillas criminales... implementan 'políticas' de reclutamiento y control de los estudiantes en las escuelas de su territorio, que se transforman en fuente de ingresos derivados de la extorsión a los estudiantes y a los maestros o de la venta extorsiva de drogas" (UNESCO 2008).

Migración de padres de familia fuera del país: En ambos escenarios, la migración hacia Estados Unidos o España por parte de los padres de familia es uno de los riesgos al que los Directores le dan más peso. Los estudiantes cuyos padres de familia han migrado tienden a presentar más conflictividad en los estudios y en la conducta, de acuerdo a los Directores: "Ahora la crisis ha hecho que el papá y la mamá trabajen mamá trabajen, aparte de que el papá se va para Estados Unidos o son madres solteras... no les dan tiempo a los hijos". Es claro para los Directores que la crisis económica subyace como causa principal de la migración; expresan el temor de que este fenómeno aumente y por tanto, más estudiantes queden a cargo de familiares o extraños que no los controlan ni los forman adecuadamente.

El papel de la disciplina escolar, violencia y bajo rendimiento: La disciplina escolar es un factor que las autoridades de los centros relacionan estrechamente con los problemas de violencia y de 
Resiliencia educativa de estudiantes ante los riesgos sociales generados por la barras juveniles de fútbol en Honduras

rendimiento académico:

Pertenencia a barras y maras: Para este otro grupo de entrevistados, es obvia la existencia de grupos que generan violencia juvenil al interior del centro:

Hay grupos separados, no sólo varones... las mujeres tienen sus grupos... ¡sí!

En ambos centros, la causa señalada para la posibilidad de ser reclutado es primordialmente la situación familiar.

Lo que hemos visto nosotros al ver esa consecuencia y esa violencia interna familiar. Lo primero casi siempre es niños que no tienen con su mamá ni su papá, niños que viven con su abuelita que tienen tíos. Esos muchachos son los que generalmente están cayendo.

Además manifiestan, que resulta difícil identificar el proceso de reclutamiento e involucración, por las señales externas en el vestir: "Yo... los identifico... usan su pantalón oscuro... andan con el peinado... siempre andan con su pelo parado y con mucha gelatina...". Además del vestir, los consejeros conocen los rituales seguidos por estos grupos:

Para integrar a un grupo los golpean, entonces ya vienen aquí golpeados... bien golpeados y... porque ese es como un ritual para poder y participar.

Lo golpean, $\mathrm{i}$ ihacen una rueda!!! Y eso por lo general no lo hacen aquí dentro si no que usted va ver acá por allá... [nombre de una colonia cercana al Instituto]... debajo del puente... por allá se van a hacer esas cosas.

Estas alusiones coinciden con lo propuesto en el estudio realizado por la Agencia Sueca de Cooperación Internacional para el Desarrollo (ASDI 2007), en el que se señala que "Ias pandillas ofrecen una identidad alternativa que se apoya sobre un vocabulario más o menos común que destaca la importancia de una serie de ritos de iniciación, 
Zoila Suyapa Padilla

normas internas de comportamiento y un lenguaje externo de identificación" (ASDI 2007). El personal de las instituciones educativas, señala que hasta ahora no han recibido formación específica para el tratamiento de estas situaciones, sin embargo se apoyan en su formación previa.

Drogas y narcomenudeo: El tema de las drogas está presente en el análisis que hacen los entrevistados. Se señala que: “

El otro tema más complicado es el de las drogas; pues nuestra población por ser la más numerosa a nivel educativo son presionados por los grupos del narco menudeo los que hacen el tráfico, ipara que ellos se involucren verdad! iya sea como mulas verdad! o como consumidores digamos esa presión aumenta año con año.

Esta opinión por parte de algunos participantes entrevistados contrasta con el informe de los estudiantes quienes no hablan explícitamente sobre este aspecto.

Riñas y peleas: Las riñas y peleas son detectadas como conductas muy frecuentes y que pueden llegar a escalar a situaciones tan violentas que requieren la intervención de la policía. En ambos centros se reporta que se dan muchos incidentes de riñas y peleas en el que están involucrados tanto los varones como las mujeres. La prevalencia de este riesgo podría considerarse como una evidencia de los rituales propios de pandillas pero también como formas de agresión adolescente que refleja el modelo de resolución de conflictos que se está desarrollando en los jóvenes.

La desintegración y la problemática familiar: La desintegración y la problemática familiar son considerados factores de riesgo relevante para este grupo de actores pues según los entrevistados:

No son muchos chicos que tienen a su mamá y papá que los atiendan, que les den todos sus estudios, su dinero para la merienda, sus libros...

Alumnos que, pobrecitos... que no tiene ni para el pasaje de venir 
al colegio y se ponen a pedir, entonces yo me imagino que lo que yo he notado que se agregan a esos grupos es porque les regal en... hacen colecta. ¿Sabía que piden a los chiquitos? A los chiquitos de primer curso, a principio de año les piden un lempira, les van a pedir a las aulas.

Resulta importante destacar que algunos jóvenes pueden simpatizar con los grupos de maras y/ o pandillas, ser amigos de ellos y pensar en algún momento en perteneces a ellas.

Algunos de los entrevistados opinan que las barras de fútbol son el disfraz de lo que se ha conocido siempre como mara y/ o pandilla. Que los jóvenes entran pensando que son simpatizantes de un grupo de fútbol. Sin embargo cuando entran se dan cuenta que esto tiene que ver con el futbol pero existen otros elementos que emergen en su momento y que muchas veces son conductas que se han identificado con los participantes en maras.

\subsection{Desde la Percepción de los Padres de Familia}

El hecho de que la familia esté atenta a las manifestaciones de los riesgos del entorno social, constituye un elemento positivo que debe ser tomado muy en cuenta por el personal de las instituciones educativas para unir los esfuerzos de prevención y mitigación de la violencia. Se encuentra, a partir de las expresiones de los padres y madres de familia de ambos centros educativos, que tanto las madres como los padres, conocen las vicisitudes a las que pueden verse sometidos sus hijos e hijas y esperan el apoyo de la escuela para enfrentar tal situación.

Los grupos focales con padres y madres de familia resaltaron la prevalencia de un nivel alto de riesgo de violencia tanto al exterior como al interior de los centros. La preocupación de los padres y madres fue muy alta en ambos escenarios, llegando a hacer catarsis de llanto en algunos de los testimonios.

Los riesgos detectados por ambos grupos focales de padres y madres fueron los siguientes: drogas, maras y barras, falta de comunicación de los padres de familia con los hijos, falta de control por los guardias 
Zoila Suyapa Padilla

o encargados de la vigilancia.

Drogas, maras y barras: Los padres de familia tienden a relacionar estos factores de riesgo:

Para los padres de familia, la forma de reclutamiento se realiza Ilamando la atención de los estudiantes y buscándolos dentro del centro:

Ellos acaparan a los muchachos, los buscan; así como escucha en la noticias eso de las maras, la revo... la ultra...esas barras que son maras.

En los centros se destacó el proceso de reclutamiento como un riesgo claramente percibido por los padres y madres en la zona sur. La causa de este temor podría estar relacionada con el mayor dominio territorial que ejercen las maras alrededor del centro educativo y en las comunidades donde éste se ubica.

La razón para el involucramiento según los padres y madres consultados, tiene que ver con necesidades económicas pues, según ellos:

Lo que les atrae a los niños a veces es el dinero. A los niños les ofrecen dinero y a ellos eso les va gustando porque los enganchan invitándolos, regalándoles y después solo le dicen, vos ya perteneces y ellos ya no pueden salir y lo único que les espera es la muerte...

Para los padres y madres el reclutamiento e involucración se facilita en el acceso a lugares como los café net, donde los estudiantes se ven obligados a ir para cumplir con tareas que les dejan en el colegio. Los padres de familia aducen que "ahora los maestros todo lo dejan para el internet y allí es donde buscan a los jóvenes para involucrarlos." También hay lugares como el rio en la zona sur o las entradas de los centros educativos.

Falta de comunicación entre padres de familia e hijos: La ausencia de uno o los dos padres de familia es considerada como factor de 
alto riesgo para que los muchachos sean víctimas de reclutamiento y persecución por grupos juveniles violentos. Sin embargo, también se valora que aun estando presentes los padres y madres si no hay conversaciones abiertas con los hij os en las que se les aconseje 0 al menos, se intercambien informaciones sobre sus actividades, el riesgo es similar a la ausencia completa.

Falta de control por los encargados de vigilancia: Para los padres y madres de los grupos focales desarrollados, los guardias y encargados de la vigilancia toleran o influyen en acrecentar los sucesos violentos al interior del centro educativo. Se manifiestan comentarios como:

Es que a veces los guardias se prestan, ellos se venden a los cipotes.

Hay guardias que les tienen miedo... a las amenazas que les hacen... ellos tienen poder.

Fíjese que aquí en el colegio hay cipotes que ya no están en el colegio y andan con el uniforme y carnet. Son cipotes que los han expulsado pero que siempre vienen al colegio...los dejan pasar los guardias.

Podemos notar que los padres y madres de familia, describen con precisión los tipos de riesgos de violencia que enfrentan sus hijos, pero al mismo tiempo identifican alternativas que podrían mitigarlos: mejorar la vigilancia, mejorar la comunicación, no reforzar los comportamientos violentos, dar asistencia socioeconómica, no exagerar el uso del internet, involucrarse en las actividades de los hijos e hijas. Estas afirmaciones resultan valiosas propuestas para las estrategias de promoción de la resiliencia educativa.

\section{Coincidencia entre los puntos de vista de los estudiantes, administración escolar, orientación y padres de familia}

Tanto los estudiantes, administradores escolares y padres de familia, coincidieron en que existen barras y maras como formas de agrupaciones de los estudiantes que esta participación es vigente 
Zoila Suyapa Padilla

tanto dentro como fuera del centro escolar. Este hecho es percibido como riesgo, por todos los miembros de la comunidad educativa.

La percepción del riesgo de las barras y maras está asociada por todos los entrevistados a amenazas a la integridad personal y a su proyecto educativo, por lo que coinciden en señalarlo como algo negativo para su vida.

Los grupos de administradores y miembros de orientación escolar entrevistados señalan la relación entre la participación en barras juveniles, maras y/ o pandillas, el índice académico y permanencia escolar. Esta relación resulta negativa en los que no son líderes, no así en éstos, pues según se manifiesta, el líder no necesariamente es un mal estudiante.

El mensaj e clave del análisis de riesgos es que la viol encia ha permeado los centros educativos. Aunque los resultados de los cuestionarios indican que la frecuencia de actos altamente violentos (asesinatos, amenazas y acosos) se concentra en un número minoritario de estudiantes, estos ya existen como posibles en el imaginario de los jóvenes. Los asaltos, peleas, drogas y alcohol, sin embargo, tienen una frecuencia mayor. Pertenecer a pandillas tiene una connotación negativa para muchos; sin embargo las barras de futbol reflejan una ambivalencia: son espacios de "encontrar amigos", aunque se reconoce que estas conllevan a peleas y violencia entre barras.

La tipología de riesgos identificada en nuestro estudio de caso hace un llamado a la posible evolución de la violencia en los centros educativos y a la necesidad de intervenir a tiempo para frenarla. Igualmente, se presenta el factor de ambivalencia de los jóvenes ante las maras y las barras-donde se entiende su papel de "pertenencia a un grupo" aun con los riesgos que esto lleva. Dar oportunidades alternas para que los jóvenes Ilenen su necesidad de pertenecer es una reflexión importante para el sector educativo y los centros escolares. En este punto pasamos en el siguiente capítulo a los hallazgos sobre la resiliencia en estos mismos jóvenes, y su búsqueda de bienestar. 
Resiliencia educativa de estudiantes ante los riesgos sociales generados por la barras juveniles de fútbol en Honduras

\section{Hallazgos del estudio: Resiliencia}

Desde la perspectiva de resiliencia de este estudio, la identificación de riesgos (capítulo anterior) es sólo una de las partes necesaria para las respuestas institucionales de protección de la niñez y la juventud. La otra parte, y quizás la más importante desde la perspectiva de resiliencia, es la identificación de las fortalezas, las oportunidades, lo valores y las múltiples maneras de afrontamiento positivo. Son precisamente estas fortalezas y acciones positivas las que pueden guiar a los sectores educativos a dar respuestas pertinentes para reducir los riesgos y mitigar su impacto negativo en poblaciones vulnerables. Por lo tanto, este capítulo presenta los hallazgos en materia de resiliencia en los dos estudios de caso. Estos hallazgos se presentan en cuatro apartados: oportunidades del centro educativo, apoyo por parte de los docentes y directores administrativos, afrontamiento y apoyo por parte de los padres de familia y finalmente las estrategias de afrontamiento positivo por parte de los estudiantes.

\subsection{La resiliencia institucional de los centros educativos: fortalezas y oportunidades}

Frente a esta situación de riesgo presente en la vida cotidiana de los centros educativos también se encuentra una riqueza de factores protectores que al ser reforzados y orientados, se constituyen en fortalezas y acciones resilientes.

Sentido de identidad con el instituto educativo: En los dos centros estudiados, el sentido de identidad con la institución juega un papel fundamental como fuente de orgullo: los 100 años de historia en Instituto Central y la autogestión del colegio en el Ricardo Soriano. En ambos institutos se consideran como reliquias las fotografías del álbum institucional, los trofeos ganados, el libro de visitantes distinguidos y el mismo uniforme.

Ambos centros educativos cuentan con sus cuadros de actividades artísticas y deportivas. La Banda de Guerra y las Palillonas de uno de los Institutos han logrado ser reconocidas entre las mejores de 
todo el país. Los grupos artísticos y deportivos proporcionan experiencias de reconocimiento y valoración de talentos y habilidades, más allá de lo académico, por lo que su valor resiliente es importante. Estos grupos se mantienen a pesar de las dificultades financieras y aun con los posibles disturbios que una congregación de espectadores pueda traer. La salida que han encontrado los directores y consej eros cuando hay presentaciones artísticas o deportivas es pedir el auxilio de la policía como custodia de la seguridad.

El sistema de becas y, hasta hace un año, el bono estudiantil, han constituido fuentes de incentivos para el rendimiento académico y la permanencia. En el último año, este escenario ha cambiado con la suspensión del bono.

\subsection{Estrategias de afrontamiento y apoyo por parte de los docentes y directores administrativos}

Los profesores y profesoras, como factor humano, constituyen un extraordinario elemento para los procesos de cambio en todo lo que es relevante en la educación, desde la enseñanza al clima de convivencia y la resolución de conflictos. Se trata, también, de un factor complej o, no sólo porque cada docente es, en su personalidad y en su formación profesional, única y relevante, sino porque en su comunicación e intercambio con otros se va produciendo un estilo de intervención educativa que marca las pautas de la educación de los estudiantes. Los propios directores, consej eros y docentes están afectados por los factores de riesgo que afectan o pueden afectar a los estudiantes. La mayoría muestra su temor a expresar abiertamente el problema de violencia pero, al mismo tiempo, al enfrentar una situación en el centro, realizan acciones de apoyo a las víctimas y de disciplinar a los responsables.

Las expectativas de futuro y satisfacción profesional de los docentes y autoridades administrativas están permeadas por la incertidumbre que los últimos cambios en las leyes educativas les ocasionan. Se mantiene, sin embargo, la solidaridad y apoyo mutuo ante situaciones de emergencia para ellos o para los estudiantes:

Los docentes y autoridades señalan que se apoyan en su fe cristiana 
y se las trasmiten a los estudiantes como un medio de protección. En el Ricardo Soriano este tipo de apoyo se hace de forma continua, leyendo con los estudiantes versículos de la Biblia y reflexionando sobre ellos:

Los padres de familia, a la vez que son señalados como factor de riesgo por parte de directores, orientadores y consejeros, también son el apoyo principal.

Capacitaciones para los estudiantes, tutorías, consejerías y reforzamiento también juegan un papel importante en el instituto educativo. El rendimiento académico es prioridad para los profesores y autoridades por lo que buscan medidas alternativas para superarlo.

Los problemas relacionados con la violencia son atendidos en Consej ería:

Cómo se resisten a esto, como lo evaden, pues creo que por convicción, además es un trabajo que se logra con consejería... pasan por las aulas, ellos dialogan con los muchachos.

Estas son las charlas que se les dan a los muchachos... Les dan consejería que no anden metidos en grupos que nada les deja, miren cuantos muertos hay, esa cantidad de muertos espantosa que uno los pone de ejemplo.

Como una medida nosotros hemos implementado la supervisión, la consejería, la orientación a los jóvenes por lo general bastante capacitación ¿verdad? sobre estos temas.

Es de hacer notar que existen programas de apoyo por parte de instituciones estatales, agencias internacionales y organizaciones no gubernamentales en ambos centros educativos. Estos programas son reconocidos como fortalezas por parte de los directivos pero no así por los estudiantes y padres de familia quienes no hacen ninguna alusión sobre los mismos. 


\subsection{Estrategias de afrontamiento y apoyo por parte de los pa- dres de familia y otros miembros de la comunidad}

Las posibilidades que tiene tanto la familia como la comunidad de generar seguridad en los adolescentes es uno de los factores de resiliencia más importantes, de acuerdo a los estudios. En la familia dos puntos son fundamentales: la comunicación con los padres de familia y el fortalecimiento de los valores y creencias. El apoyo parental, las actividades prosociales y la asistencia centros religiosos, tienen un efecto positivo en la socialización de los adolescentes (Ostaszewski y Zimmerman 2006).

Es así que, derivado del entorno familiar que encontramos en ambos centros, aun con las problemáticas de migración fuera del país de muchas familias, el trabajo fuera del hogar de ambos padres y la desintegración familiar, los padres de familia reconocen que ellos son fuente primordial de protección y tratan de hacer su parte.

En relación al fútbol y la violencia, los padres de familia señalan que están ejerciendo mayor cuidado y los acompañan personalmente a los partidos.

Los grupos focales con los padres y madres evidencian la capacidad que muchas familias tienen de hacer frente a la problemática de forma intuitiva, ya que no cuentan con un sistema efectivo y continuo de aconsejamiento, además de la iglesia a la que acuden.

\subsection{Estrategias de afrontamiento por parte de los estudiantes}

Identidad con el país: El sentido de pertenencia a su país, es decir, la identidad nacional, es un elemento que aparece como motivo de orgullo en los estudiantes entrevistados. Este sentimiento aparece altamente significativo, considerando la fragilidad del contexto social en el que conviven los estudiantes encuestados.

Propósito de futuro: En ambos institutos, los estudiantes señalaron tener como principal meta para su futuro continuar su educación. En el caso del Instituto Central Vicente Cáceres un 51\%señala tener una meta más alta que la Licenciatura. Este porcentaje es de 41. 9 
en el Instituto Ricardo Soriano, lo que demuestra similaridad en las aspiraciones. Según estos hallazgos, la educación es percibida por los estudiantes como un proyecto muy valorado en sus metas de vida. Para los estudiantes, lograr la oportunidad de educarse es altamente valorada por estar asociada a mejor estatus social y mayores ingresos. Además, según lo demuestran los porcentajes de respuestas positivas, la mayoría cree que va a lograr esta meta en su vida.

Conexiones y vínculos: Tanto varones como mujeres valoraron alta su conexión con la familia, más en el aspecto psicológico que material, pues reconocen las dificultades económicas en las que viven. Aun cuando la mayoría señala que no puede hablar de sus problemas con la familia, la familia sigue constituyendo para este grupo de adolescentes su fuente de referencia para protección, sea ésta representada por los padres de familia mismos o por una figura sustituta como la de un tío. Unida a la familia está la conexión con la iglesia. Según refieren, en algunas iglesias encuentran además del sostén espiritual, ayuda material para solventar ciertas necesidades.

La conexión con sus profesores aparece alta, pues los estudiantes encuestados señalan que buscarían a sus profesores si tuvieran problemas que no tuvieran que ver con tareas del instituto. Se reconoce que la figura del maestro sigue jugando un papel de referencia para los estudiantes de esta edad a pesar de que los mismos profesores no se sienten muy seguros de poder intervenir en situaciones relacionadas con violencia juvenil.

Igual referencia se ofrece acerca de los amigos a quienes los estudiantes califican muy alto en relación a confianza para hablar con ellos acerca de sus problemas.

Autopercepción: La mayoría de los estudiantes señala que se siente seguro y consciente de sus fortalezas, sin embargo no siente que tienen muchas oportunidades para demostrarlo. El sistema de control disciplinario es bastante fuerte y el exceso de peso académico no les da mucho espacio para demostrar sus talentos a pesar de que si aprecian el que haya cuadros deportivos y artísticos. 
Habilidades personales y sociales: Los estudiantes aprenden desde muy temprano a reconocer las señales de peligro en el ambiente. Sin embargo, les toma más tiempo saber cómo defenderse pues estas situaciones de violencia juvenil, por lo regular, no son discutidas explícitamente dentro de la familia o escuela. Cuando las familias o los centros lo hacen, la diferencia es muy grande en preparar y proteger psicológicamente a los estudiantes. El mecanismo principal que aprenden lo adolescentes es el de evitar sin confrontar. Es decir, al ser abordados para reclutamiento, encuentran una forma no violenta de enfrentar esta provocación.

El papel de la comunidad, es a la vez un factor de riesgo como de protección. Es de riesgo porque en ella enfrentan todo tipo de peligros a su integridad física, psicológica y moral. Cada día para los estudiantes significa sortear una serie de peligros antes de llegar al centro de estudios: asaltos, robos, intimidaciones, etc. Pero a la vez, es en la comunidad cercana, sobre todo las iglesias, donde encuentran su principal fuente de respaldo además de la familia. Las creencias religiosas unidas al efectivo apoyo material que brindan algunas iglesias a los jóvenes de esta edad constituyen una especie de escudo que por lo menos, les brinda una moratoria para prepararse ante la adversidad.

\section{Recomendaciones para una política estratégica}

Este estudio se inició identificando los riesgos que enfrentan los estudiantes hondureños ante la creciente ola de violencia en el país. El abordaje principal que se pretendía era entender la violencia generada por exposición a las barras juveniles y la incidencia de la "cultura de pandillas" en los centros educativos. Las barras de fútbol, en este contexto, son una estructura que permiten a algunos estudiantes pertenecer a un grupo y buscar protección en ellas. Dicho sentido de pertenencia es un factor de resiliencia ante la adversidad. Sin embargo, las barras de fútbol y otras agrupaciones de jóvenes pueden ser permeadas por los riesgos, incluyendo la violencia. Por lo tanto, el mensaje más importante es que los sistemas educativos deben proveer alternativas para llenar la necesidad de los estudiantes de pertenecer a un grupo-que los entienda, los proteja, y los ayude a afrontar en conjunto las adversidades. Sin 
estas estructuras de grupo, los jóvenes buscarán sus propios medios para llenar esta necesidad. Tal aporte del sistema educativo requiere una actuación integral que debe unir las diversas piezas involucradas siguientes:

a) Las diversas dimensiones de las escuelas (académica, social, administrativa) integrada como un proyecto integral de formación para la vida.

b) La necesaria diversidad de actores y de respuestas orientadas y dirigidas hacia un mismo fin: la construcción cotidiana de convivencia y de climas escolares favorables al aprendizaje.

c) La acción preventiva y restauradora en materia de conflictos y violencia como una pieza, que aunque importante, no debe ser tratada separadamente de las anteriores.

Con base a lo anterior, extraemos de nuestro estudio varios principios útiles para políticas educativas en distintos niveles del sistema:

Recomendaciones de Política Educativa: Para los Centros, Para la Preparación del Personal Docente, y para el Sistema Educativo

Al analizar los hallazgos encontrados en el estudio, se evidencian una variedad de elementos implicados que nos pueden ayudar a comprender desde la mirada de los actores, la complejidad de los procesos de convivencia educativa en contextos de violencia social y juvenil. En ambos escenarios, se muestran muchas similitudes en las causas, el impacto y los mecanismos de afrontamiento. Algunas particularidades aparecen en cuanto a los recursos de afrontamiento y la viabilidad de las respuestas. A continuación detallamos estas implicaciones.

\section{Para los centros educativos:}

Se muestra evidente que el riesgo de exposición a las pandillas y barras juveniles es un hecho existente en estos centros educativos. Este hecho es percibido como riesgo por todos los actores pero el grado de reconocimiento es variable debido al temor de sufrir las consecuencias de delatar o denunciar cualquier situación relacionada. Para las autoridades, maestros y consejeros implica un asunto de 
seguridad personal e institucional, fundada en que no se cuenta con una estrategia sólida de protección que garantice que no habrá consecuencias lamentables si lo hacen. Se requiere a corto plazo una estrategia integrada de prevención, protección y respuesta, tanto al interior como al exterior de las instituciones educativas, sobre todo de aquellas ubicadas en las zonas de mayor riesgo.

Preparación del personal docente

Las evidencias demuestran que no se lleva un adecuado control, registro 0 análisis de la frecuencia, intensidad y tipo de situaciones generadas por la violencia de maras y pandillas al interior de los centros educativos, por lo que se vuelve más difíciles de anticipar la evolución de los hechos y responder apropiadamente a los mismos. La mayoría del cuerpo docente no cuenta con herramientas técnicas para afrontar el tema de las barras y pandillas, su naturaleza y relación con la violencia juvenil y social. Utilizan la base de conocimientos generales de su profesión, lo que en las circunstancias actuales no resulta suficiente 0 actualizado. En este sentido, una preparación específica y directa del personal se hace necesaria, como parte del proceso de formación inicial y en servicio.

Establecer alianzas y coordinar relaciones entre los actores para mejor el clima escolar

Siendo que los determinantes del riesgo de violencia por barras y maras son estructurales (ausencia de espacios para socialización apropiada, procesos de exclusión económica y social, cultura de la pandilla, etc. ), la población que atiende estos centros educativos es impactada por estas causas, en especial en la franja de edad de los participantes del estudio. Para los centros educativos es muy difícil dar atención a estas necesidades, las que al mismo tiempo son determinantes para el aprendizaje. En ambos institutos se buscan formas creativas de ofrecer apoyo material, espacios de recreación y demostración de talentos. Dada la intensidad de la problemática, se necesita establecer alianzas más fuertes entre programas de la comunidad y los centros educativos para incidir sobre estos determinantes y dar un mensaje de protección a sus estudiantes y sus familias. 
Además de incidir en los determinantes estructurales, la relación directa entre actores del proceso educativo es indispensable. En los centros estudiados existen diferencias de aproximación y comunicación entre los actores debido a la cantidad de estudiantes y la complej idad del centro. En la zona sur esta comunicación resulta más fácil porque hay menos estudiantes y el centro está localizado en la misma comunidad de donde proceden los estudiantes. Sin embargo, se vuelve más difícil si los padres de familia trabajan 0 viven fuera de la comunidad. Dado que la comunicación con las familias es indispensable, deben buscarse alternativas para intercambiar señales de alerta temprana, estrategias de intervención y apoyo directo en caso necesario. Para ello las autoridades educativas, los docentes y otro personal, deben estar preparados técnica y emocionalmente para conducir procesos de acompañamiento familiar.

Implementar un modelo de disciplina positiva

Al interior de los centros educativos, el clima escolar y de gestión de la convivencia resulta clave para prevenir y mitiga el problema de la violencia juvenil. Es claro que el tipo de relación maestroalumno hace la diferencia en la incorporación de patrones de socialización entre los adolescentes. Contar con un modelo de disciplina positiva, con múltiples opciones y basada en fortalecer las habilidades sociales más que en penalizar, es pieza clave en el proceso de convivencia. Esto implica la revisión del modelo disciplinario que se está utilizando a nivel general en los centros educativos y superar el ambiente de contención excesiva en una edad que exige muchos espacios para el intercambio, la expresión de emociones y la realimentación de otros mediante el dialogo formativo o la corrección rehabilitadora, basada en respuestas resilientes.

\section{Para los jóvenes y sus familias}

Las familias de ambos centros comparten el hecho de verse expuestas igual que sus hijos, a la espiral de violencia social por lo que la violencia juvenil derivada de barras juveniles, maras y pandillas no les resulta aj ena, como lo expresaron los grupos focales de padres y madres. Para muchas familias, la disyuntiva se presenta entre dedicar 
tiempo a estar cerca de sus hijos o poner todos sus esfuerzos en luchar por la sobrevivencia. Resolver este dilema entre un extremo u otro puede significar pérdida de la base de sustentación psicológica o financiera de la familia. Sin ayuda externa, este dilema lleva al desgaste y algunas veces, a rendirse ante el reclutamiento e intimidación, lo que implica la urgente necesidad de brindar apoyo sistemático, tanto general como selectivo, a las familias de los estudiantes que acuden a los centros de enseñanza.

Formar a los padres de familia

Se hace notoria la mínima formación con la que cuentan los padres de familia para afrontar problemas de exposición a la violencia por parte de sus hijos e hijas. Esta formación es la que han recibido de las iglesias o la que han recibido trans-generacionalmente. Sin embargo, es poca la formación recibida desde el centro educativo donde acuden sus hijos, muchas veces limitada a información general sobre el rendimiento de los mismos o a quejas sobre sus conductas. Las implicaciones de la falta de conocimientos específicos para manejar la exposición a la violencia acrecienta el hecho de no atender de forma temprana las señales ni tener o buscar alternativas de intervención cuando el problema ya está presente. Más aun, impide establecer las bases familiares para la construcción de mecanismos resilientes desde el principio y de ir adecuando éstos según las circunstancias, como parte de un proceso de aprendizaje vital.

Facilitar actividades entres padres de familia y hijos

Un elemento importante en el papel de las familias es la disponibilidad de actividades conjuntas entre padres de familia e hijos. Cuando ambos comparten actividades como ir juntos a los partidos de futbol o compartir salidas a centros de recreación, las oportunidades de disminuir el riesgo aumentan, por cuanto es entonces que los padres de familia aprovechan para mostrar y modelar en sus hijos comportamientos protectores. Dado que este tipo de convivencia resulta poco frecuente es esencial el acompañamiento del centro escolar para facilitar encuentros intergeneracionales en actividades no escolarizadas, encaminadas específicamente a favorecer la 
socialización. Debe darse prioridad a estas áreas, que hasta ahora están menos apreciadas que las áreas académicas, tanto en tiempo como esfuerzos.

Proveer educación familiar a través de alianzas

El patrón familiar centrado en el machismo y el autoritarismo tiene una alta influencia en los patrones de convivencia que los jóvenes internalizan. Poco se ha logrado en re orientar este modelo, por lo que, al ser sometidos a vivencias de este tipo, los adolescentes son presa fácil de una cultura de pandillas que lo reproduce, aún cuando al inicio se ofrezca como vía de escape a la represión y al control familiar. Es aquí donde, de nuevo, la educación familiar debe ir a la par de la educación puramente escolarizada, tanto para los padres de familia como para los hijos e hijas, lo que implica que deben darse alianzas entre los organismos que trabajan con familias y las instituciones educativas.

\section{Acciones de estrategia política pública}

El modelo de la Resiliencia surge desde el análisis realizado en el presente estudio como un facilitador de esa visión integral entre lo académico y lo socioemocional ante el problema de la exposición a la violencia que incide en la comunidad educativa. Esta visión requiere concretarse en acciones de estrategia política desarrollada por el sistema, desde ejes orientadores como:

Creación de un entorno seguro

Las instituciones educativas por contener dentro de si durante un amplio lapso de tiempo a la mayor cantidad de niños, niñas, adolescentes y jóvenes del país con sus respectivas familias, es el espacio social por excelencia para ofrecer un entorno de seguridad física, social y psicológica. Este proceso comienza por reconstruir el entorno seguro en el imaginario de los actores con acciones estratégicas encaminadas a favorecer cambios, como los siguientes:

a) Cambio en el sentido de las reglas disciplinarias, desde un sentido punitivo a uno asociado a un bien común co-construido y valorado 
Zoila Suyapa Padilla

desde su orientación ética, con responsabilidad por los otros y por la construcción de la comunidad.

b) Cambio en el uso y distribución del espacio físico del centro educativo y de su entorno inmediato, lo que significa recuperar los espacios de socialización como tales, y asegurar las entradas y salidas sin efecto carcelario pero con controles apropiados.

c) Cambio en el abordaje pasando de un afrontamiento reactivo a un afrontamiento preventivo, con acciones sistemáticas dirigidas a identificar a tiempo las señales y el registro y análisis periódico de las mismas.

Construcción de oportunidades de desarrollo de talentos

El proyecto educativo además de procurar el rendimiento académico, debe asumir la responsabilidad por la formación integral de los adolescentes dando amplias oportunidades para el desarrollo de los talentos, la expresión de emociones, el entrenamiento en habilidades sociales, la participación y la toma de decisiones, que culminen con la planificación de un proyecto de vida. También debe incluir un menú variado de opciones para los estudiantes que requieran, durante su período de formación, apoyos orientados a mejorar sus aprendizaj es y rehabilitar patrones de comportamiento conflictivos si los tuviera. Estas oportunidades deben formar parte de la gestión del currículum y no tratarse como actividades extracurriculares donde se invisibilízan.

Abordar un enfoque sistémico de protección frente a la violencia

La aplicación de un enfoque más sistémico y holístico de protección dentro de los centros educativos permite realizar un análisis de la relación riesgo-protección de forma exhaustiva y contextualizada. Esto significa que cada centro debe conformar una red de coordinación con instituciones gubernamentales y no gubernamentales que intervienen en el tema de prevención y mitigación de la violencia así como de aquellas que generan oportunidades para los jóvenes. En este sentido, los centros educativos aparecen como una institución fundamental en la creación de espacios de intercambio con las familias y con el municipio, lo que configura una línea principal de trabajo. El papel de las universidades es importante para la 
generación de conocimiento a través de estudios dirigidos a conocer cada uno de los escenarios y sus factores asociados.

Desarrollo de competencia técnica sobre respuestas desde la resiliencia

La protección de los estudiantes-y en particular su preparación para afrontar la exposición a la violencia-requiere un nivel de competencia técnica en el majeo de estrategias resilientes. Además de que las comunidades educativas posean conocimientos de la gestión curricular, se requiere una formación similar en la competencia específica necesaria para el proceso de prevención y manejo de crisis, resolución positiva de conflictos, análisis y gestión de riesgos sociales, estrategias para el manejo de la violencia juvenil. Existen programas regionales e internacionales ya establecidos y con capacidad de compartir sus experiencias en el tema que podrían servir de base para un modelo contextualizado de resiliencia educativa.

Participación y responsabilización de los jóvenes

La propuesta descansa en la concepción de que la participación de los jóvenes en la formulación de estrategias resilientes es fundamental para la construcción y el desarrollo de la formación ciudadana. La participación pone en marcha lo mejor del estudiante porque lo compromete desde su unicidad y le permite que, mediado por un adulto o un compañero, pueda construir su comprensión de su rol social. Esta participación es entendida como un diálogo permanente entre el mundo de los adultos y el de los jóvenes.

\section{Para el país}

Desarrollar más herramientas para entender y afrontar la violencia desde un abordaje de Resiliencia educativa

La comunidad nacional está cada vez más informada sobre la alta exposición a la violencia que viven la ciudadanía y en particular, los jóvenes. Tal cobertura informativa proviene sobre todo de los medios de comunicación de masas. A nivel general se han dado pasos en 
priorizar el problema, mejorar los registros y evidenciar las manifestaciones diversas que toma la violencia. Sin embargo, es muy poco lo que se ha estudiado en el país acerca de cómo se presentan estas situaciones en los centros educativos.

Las implicaciones de la falta de análisis confluyen en que los actores de la comunidad educativa se encuentren con pocas herramientas para entender y afrontar la problemática derivada de la exposición a la violencia, y por tanto, la respuesta de cada uno de ellos es insuficiente ante la incidencia y prevalencia de los riesgos.

Conducir análisis de la exposición a la violencia de los estudiantes

Aunque el problema de la violencia juvenil, como tal como lo testimonian los actores, tiene raíces estructurales, las respuestas son individuales pues no se cuenta con una estrategia concertada. Este tipo de afrontamiento refuerza la vulnerabilidad de los centros educativos y de los involucrados a medida que la problemática avanza. Resulta fundamental para el país, conducir análisis de la exposición a la violencia que viven los estudiantes de los diversos centros educativos desde la mirada de la resiliencia ya desarrollada por ellos, sus profesores y sus familias y la resiliencia que podría generarse si se refuerzan los factores protectores y se generan nuevas oportunidades todavía no presentes, como por ejemplo, una política de actuación estratégica para fortalecer desde la educación el valor de la vida humana.

\section{Conclusiones}

Concluimos este estudio con 10 principios generales extraídos de los hallazgos de este estudio.

- En los dos escenarios se percibe la exposición a la violencia originada por barras juveniles como uno de los riesgos que afecta a la comunidad educativa; sin embargo, la afiliación a las barras juveniles también demuestra la necesidad de los jóvenes de pertenecer a un grupo, especialmente al enfrentar un contexto de vida difícil.

- La percepción de riesgo ante las barras juveniles varía en el 
grado en que es manifestada abiertamente por los actores, dependiendo del temor asociado y del sentimiento de vulnerabilidad ante el mismo. Aún cuando la mayoría de los estudiantes en los dos estudios de caso no pertenece a barras juveniles o pandillas, la mayoría si conoce del fenómeno y tiene información clara sobre él.

- Se muestra consenso entre todos los participantes en señalar el entorno externo al centro educativo como el espacio de mayor riesgo para la exposición a la violencia. Aunque la institución educativa también es una localidad donde la violencia se manifiesta, los estudiantes aún ven el espacio escolar como un espacio de protección ante los riesgos en las calles.

- Las principales causas de la involucración en barras juveniles y pandillas a la que aluden los participantes son los modelos de desintegración familiar, la intimidación o acoso provocados por el reclutamiento, la búsqueda de poder y liderazgo, y la solución a problemas económicos. Sin embargo, estos espacios también son considerados como una alternativa de pertenecer a un grupo y de buscar protección y/ o control sobre un mundo de adversidad fuera de control.

- En ambos centros educativos más del 90\% de los estudiantes consultados señalan no estar involucrados en las barras o pandillas; la mitad de ellos señalan que conocen compañeros o amigos que si lo están. Se evidencia que las pandillas y barras juveniles actualmente forman parte del imaginario de los estudiantes y una opción de pertenencia si el sistema educativo no les brinda otras alternativas más funcionales.

- Toda la población consultada rechaza la afiliación a barras y maras como una forma apropiada de socializar o resolver problemas. A la vez señalan la necesidad de contar con al ternativas saludables y de bienestar como los clubes estudiantiles, espacios para desarrollar su liderazgo, oportunidades de auto-gestión y expresión de talentos.

- Los padres de familia y los estudiantes son los actores que reportan conocer con mayores detalles los mecanismos de afiliación y retención utilizados por las barras y pandillas juveniles, como evidencia de vivir de manera cotidiana en un ambiente de riesgos. A su vez, tanto los padres de familia como los estudiantes presentan propuestas concretas sobre cómo afrontar los riesgos de manera positiva. 
- Los estudiantes y sus familias señalan como factores protectores para afrontar la exposición a barras y maras: las creencias religiosas, el apoyo de amigos, el apoyo de personas de la comunidad y las metas orientadas a completar el proyecto educativo. Desde su perspectiva el sector educativo estaría llamado a ampliar sus estrategias académicas con elementos socio-emocionales que fomenten y fortalezcan estos factores protectores.

- Para los docentes y las autoridades de los centros, el sector educativo puede definir políticas educativas, promover programas y establecer estructuras institucionales que fomenten la relación entre la mitigación de la prevalencia de factores de riesgo, el fomento de factores protectores, la disponibilidad de oportunidades y el fortalecimiento de condiciones personales resilientes.

- Todos los participantes coinciden en que el punto de partida para un sector educativo hondureño que fomente la resiliencia es articular una política sectorial respecto al tema, con un enfoque que reconozca los riesgos pero también los mecanismos resilientes que existen en la comunidad, la institución educativa y los actores, misma que debe ser basada en estudios contextualizados, tomando en cuenta la región geográfica y la modalidad educativa. 


\section{Referencia}

Aber, J. L., J. L. Brown and S. M. Jones. 2003. "Developmental trajectories toward violence in middle childhood: Course, demographic differences, and response to school-based intervention." Developmental Psychology 39(2):324-348.

Argueta, S. 1991. “Diagnóstico de los grupos llamados 'maras' en San Salvador. Factores psicosociales que prevalecen en los jóvenes que los integran." Revista de Psicología de El Salvador 2(43):53-84.

ASDI, Agencia Sueca de Cooperación Internacional para el Desarrollo. 2007. Maras y pandillas, comunidad y policía en Centroamérica. Hallazgos de un estudio integral. http:/ / www. ocavi.com/ docs_files/ file_539. pdf

Barrón, M., M. Carboneti, G. Cardozo y otros. 2003. Impacto de la Inequidad Sociocultural sobre el Riesgo y Resiliencia en Adolescentes: Violencia y Adicciones. Córdoba: SECYT.

Belanger, M.L. 2008. Creando Resiliencia Frente a Desastres e Inseguridad Alimentaria en Guatemala. Guatemala: Cruz Roja Guatemalteca.

Benbenishty, R., y R.A. Astor. 2008. "School violence in an international context: A call for global collaboration in research and prevention." Presentado en la Conferencia Mundial IV Violence at school: Violence in context? Lisboa, Portugal.

Benard, B. 2004. Resiliency: What We Have Learned. San Francisco: WestEnd.

Blanco, M.T. 2006. Relaciones de Violencia entre Adolescentes: Influencia de la Familia, la Escuela y la Comunidad. Buenos Aires: Espacio Editorial.

Blum, R. 1997. "Riesgo y resiliencia." Adolescencia Latinoamericana 1(1): 16-19. 
Zoila Suyapa Padilla

Borum, R. 2003. "Managing at-risk juvenile offenders in the community: Putting evidence-based principles into practice." J ournal of Contemporary Criminal J ustice 19(1): 114-137.

Catalano R. F., R. Loeber, and K.C. McKinney. 1999. "School and community interventions to prevent serious and violent offending." J uvenile J ustice Bulletin OJ JP 1(11).

CEPAL, Comisión Económica para América Latina. 2008. Panorama Social de América Latina. Santiago de Chile.

Diario La Prensa, San Pedro Sula Honduras. 2012. Serie de Investigación Documental: Sitiados Centros Educativos por las Maras. 10 de Septiembre.

Evans S.W., and M.D. Weist. 2004. "Implementing empirically supported treatments in the schools: What are we asking?" Clinical Child and Family Psychology Review 7:263-7.

Fumero, M. 2011. El Abuso de Autoridad. Tegucigalpa: Producciones Peniel.

Henderson, N. y M.M. Milstein. 2003. Resiliencia en la Escuela. México: Paidós.

INE, Instituto Nacional de Estadísticas. 2008. Encuesta Permanente de Hogares de Propósitos Múltiples. Tegucigalpa, Honduras.

J asuja, G. K., C.P. Chou, K. Bernstein, E. Wang, M. McClure and M.A. Pentz. 2005. "Using structural characteristics of community coalitions to predict progress in adopting evidence-based prevention programs". Evaluation and Program Planning 28: 173-184.

Kazdin, A. E., A. Rodgers, and D. Colbus. 1986. "The hopelessness scale for children: Psychometric characteristics and concurrent validity." J ournal of Consulting and Clinical Psychology 54: 241-245.

Kornblit, A.L. 2000. Sida: Entre el Cuidado y el Riesgo. Buenos Aires: Ed. Alianza. 
Kumpfer, K. L. and R. Alvarado. 2003. "Family strengthening approaches for the prevention of youth problem behaviours." American Psychologist 58(6/7): 457-465.

Masten, A. y J. Obradovic. 2006. "Competence and resilience in development." Annals of the New York Academy of Sciences 1094(1): 13-27.

Moser, C. 1999. "La violencia en Colombia: Cómo construir una paz sostenible y fortalecer el capital social". Ensayos Sobre Paz y Desarrollo. El caso de Colombia y la experiencia internacional. El Banco Mundial.

Nagel T., G. Robinson, J. Condon and T. Trauer. 2009. "Approach to treatment of mental illness and substance dependence in remote Indigenous communities: Results of a mixed methods study." Australian J ournal of Rural Health 17: 174-82.

Observatorio Nacional de la Violencia. 2011. Boletín del Observatorio Nacional de la Violencia. Edición 24. IUDPAS. Universidad Nacional Autónoma de Honduras. Tegucigalpa.

OMS, Organización Mundial de la Salud. 2001. Enfoque de Habilidades para la Vida para un Desarrollo Sustentable de Niños y Adolescentes. Ginebra.

Ostaszewski, K., y M.A. Zimmerman. 2006. "The effects of cumulative risks and promotive factors on urban adolescent alcohol and other drug use: a longitudinal study of resiliency." American J ournal of Community Psychology 38:237-249.

Periódico Proceso Digital. 2013. Las barras están terminando de sepultar el fútbol hondureño. Sección de Deportes, 23 de Febrero. http: / / www. proceso. hn/ 2013/ 02/ 23/ Deportes/ Las. barras. est/ 64745. html

Reyes, J. 2013. What Matters Most for Education Resilience: A Framework Paper. Washington, DC: The World Bank, Education Resilience Approaches (ERA) Program. 
Zoila Suyapa Padilla

Rodgers, D. 1999. Youth Gangs and Violence in Latin America and the Caribbean: A Literature Survey. Washington, DC: The World Bank.

Schaeffer, C. M., E. Bruns, M. Weist, S.H. Stephan, J. Goldstein, and Y. Simpson. 2005. "Overcoming challenges to using evidencebased interventions in schools." J ournal of Youth and Adolescence $34(1): 15-22$.

Secretaría de Educación de Honduras. Portal de Estadísticas. http:/ / estadísticas.se.gob.hn, visitado en 2012.

Suárez Ojeda, E. N., y D. Krauskopf. 1995. "El enfoque de riesgo y su aplicación a las conductas del adolescente: Una perspectiva psicosocial." Publicación Científica No. 552, OPS/ OMS. Washington DC.

Trudel, M. and G. Puentes-Neuman. 2000. "The contemporary concepts of at risk children: Theoretical models and preventive approaches in the early years." PECERA Symposium Report: Children and Youth at Risk. Canadian Education Statistics Council.

ht t p: / / ww w. cmec.ca/ stats/ pcera/ symposium 2000/ report2000.en.pdf

UNESCO. 2008. El Último Reducto: Escuelas Públicas en Tiempos del Narco: Apoyos desde el Programa de Gobernabilidad y Liderazgo para la Convivencia Democrática. Santiago de Chile.

UNESCO/OREALC. 2008. Informe SERCE. Santiago de Chile.

UNICEF. 2012. Observatorio de los Derechos de la Infancia y la Adolescencia en Uruguay. Montevideo, Uruguay.

Ungar, M. 2005. "Pathways to resilience among children in child welfare, corrections, mental health and educational settings: Navigation and negotiation." Child and Youth Care Forum 34(423): 423444.

Ungar, M., M. Brown, L. Liebenberg, R. Othman, W. M. Kwong, M. Armstrong and J. Gilgun. 2007. "Unique pathways to resilience 
across cultures." Adolescence (San Diego): an international quarterly devoted to the physiological, psychological, psychiatric, sociological, and educational aspects of the second decade of human life 42(166): 287.

Ungar, M., and L. Liebenberg. 2011. "Assessing resilience across cultures using mixed methods: Construction of the child and youth resilience measure." J ournal of Mixed Methods Research 5(2): 126149.

Valikangas, L. 2010. The Resilient Organization: How Adaptive Cultures Thrive Even When Strategy Fails. McGraw-Hill.

Walsh, F. 1996. "The concept of family resilience: Crisis and challenge." Family Process 35: 261-281.

Walsh, F. (ed.). 1999. Spiritual Resources in Family Therapy. New York: Guilford Press.

Walsh, F. 2005. Resiliencia Familiar: Estrategias para su Fortalecimiento. Buenos Aires: Editorial Amorrortu. 